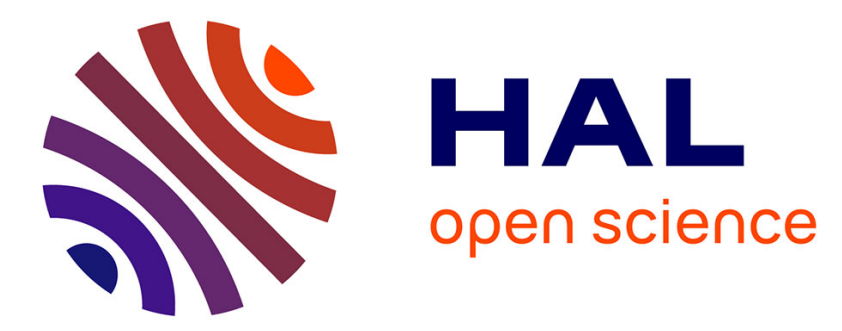

\title{
Multispecies integrated population model reveals bottom-up dynamics in a seabird predator-prey system
}

Maud Quéroué, Christophe Barbraud, Frédéric Barraquand, Daniel Turek, Karine Delord, Nathan Pacoureau, Olivier Gimenez

\section{- To cite this version:}

Maud Quéroué, Christophe Barbraud, Frédéric Barraquand, Daniel Turek, Karine Delord, et al.. Multispecies integrated population model reveals bottom-up dynamics in a seabird predator-prey system. Ecological monographs, 2021, 91 (3), pp.1-17. 10.1002/ecm.1459 . hal-03367131

\section{HAL Id: hal-03367131 \\ https://hal.science/hal-03367131}

Submitted on 11 Oct 2021

HAL is a multi-disciplinary open access archive for the deposit and dissemination of scientific research documents, whether they are published or not. The documents may come from teaching and research institutions in France or abroad, or from public or private research centers.
L'archive ouverte pluridisciplinaire HAL, est destinée au dépôt et à la diffusion de documents scientifiques de niveau recherche, publiés ou non, émanant des établissements d'enseignement et de recherche français ou étrangers, des laboratoires publics ou privés. 
1 Running head: Multispecies integrated population model

2 Multispecies integrated population model reveals bottom-up dynamics in a seabird predator-prey

3 system

4

5 Maud Quéroué ${ }^{1}$, Christophe Barbraud ${ }^{2}$, Frédéric Barraquand ${ }^{3}$, Daniel Turek ${ }^{4}$, Karine Delord ${ }^{2}$,

$6 \quad$ Nathan Pacoureau ${ }^{5}$, Olivier Gimenez ${ }^{1}$

$8{ }^{1}$ CEFE UMR 5175, Univ Montpellier, CNRS, EPHE, IRD, Univ Paul Valéry Montpellier 3,

9 Montpellier, France

$10{ }^{2}$ Centre d'Etudes Biologiques de Chizé (CEBC), UMR 7372, CNRS-Université de La Rochelle,

1179360 Villiers-en-Bois, France

12 Institute of Mathematics of Bordeaux, CNRS, Talence, France

$13{ }^{4}$ Department of Mathematics and Statistics, Williams College, Williamstown, MA, USA

$14{ }^{5}$ Department of Biological Sciences, Earth to Ocean Research Group, Simon Fraser University,

15 Burnaby, British Columbia, Canada

16

17 Correspondence author: Maud Quéroué, CEFE UMR 5175, Univ Montpellier, CNRS, EPHE,

18 IRD, Univ Paul Valéry Montpellier 3, Montpellier, France

19 E-mail: maud.queroue@gmail.com 


\section{Abstract}

21 Assessing the effects of climate and interspecific relationships on communities is challenging

22 because of the complex interplay between species population dynamics, their interactions, and

23 the need to integrate information across several biological levels (individuals - populations -

24 communities). Usually used to quantify species interactions, integrated population models

25 (IPMs) have recently been extended to communities. These models allow fitting multispecies

26 matrix models to data from multiple sources while simultaneously accounting for various sources

27 of uncertainty in each data source. We used multispecies IPMs accommodating climate

28 conditions to quantify the relative contribution of climate vs. interspecific interactions on

29 demographic parameters, such as survival and breeding success, in the dynamics of a predator-

30 prey system. We considered a stage-structured predator-prey system combining 22 years of

31 capture-recapture data and population counts of two seabirds, the Brown Skua (Catharacta

32 lönnbergi) and its main prey the Blue Petrel (Halobaena caerulea) both breeding on the

33 Kerguelen Islands in the Southern Ocean. Our results showed that climate and predator-prey

34 interactions drive the demography of skuas and petrels in different ways. The breeding success

35 of skuas appeared to be largely driven by the number of petrels and to a lesser extent by

36 intraspecific density-dependence. In contrast, there was no evidence of predation effects on the

37 demographic parameters of petrels, which were affected by oceanographic factors (chlorophyll a

38 and sea surface temperature anomalies). We conclude that bottom-up mechanisms are the main

39 drivers of this skua-petrel system. We discuss the mechanisms by which climate variability and

40 predator-prey relationships may affect the demographic parameters of these seabirds. Taking into 
41 account both species interactions and environmental covariates in the same analysis improved

42 our understanding of species dynamics.

43 Keywords: Bayesian inference, Demography, Environmental variations, Integrated Population

44 Model, Matrix population model, Nimble, Predator-Prey interactions

\section{Introduction}

46 The effects of climate change on the diversity and the structure of communities have been

47 reported repeatedly (Walther et al. 2002, Parmesan 2006, Hoegh-Guldberg and Bruno 2010,

48 Miller et al. 2018). However, the underlying mechanisms remain poorly understood due to the

49 complex dynamics of interacting species: within species, between species and between species

50 and the environment (Godfray and May 2014). Following disturbance, the abundance and

51 distribution of species are expected to be modified according to the position and extent of the

52 species' niche (Thomas et al. 2004). Because the effects of environmental variability on

53 mortality, fecundity and dispersal may differ between species (Grosbois et al. 2008, Jenouvrier

54 2013), changes in structure and diversity appear at the community level. However, studying

55 species-by-species responses to environmental changes may overlook the role played by species

56 interactions on those responses, and contribute to a lesser extent to the larger understanding of

57 species interactions that is required by community ecology.

58 Models for population dynamics have been used to understand the effect of interspecific

59 interactions and environment on species demography. However, these models are generally not

60 demographically structured (Stenseth et al. 2015, Pacoureau et al. 2019a, Stoessel et al. 2019) or

61 only partially (Millon et al. 2014, Saunders et al. 2018, Pacoureau et al. 2019b). Unstructured 
62 approaches consider individuals as being equivalent but differences in size, age and ontogenic

63 stages exist within a population and may be of importance in the context of interspecific

64 interactions. As argued by Miller and Rudolf (2011), the consideration of the stage structure of

65 populations can lead to a better understanding of community structure and dynamics.

66 Interactions between species such as predation or competition do not necessarily have a

67 homogeneous impact on the different stages of the interacting species. For example, young

68 individuals might be predominantly preyed upon in carnivore-ungulate systems (Gervasi et al.

69 2015). Therefore, to detect and understand species interactions, we need to consider jointly the

70 demography of several stage-structured populations (Oken and Essington 2015).

71 Although well developed for single-species dynamics (Tuljapurkar and Caswell 1997, Caswell

72 2001), demographic stage-structured models have received little attention in community ecology

73 (but see Chu and Adler (2015) on a plant system). The difficulty is that multispecies

74 demographic analysis requires integrating information across several biological levels

75 (individual - population - community) which, in turn, requires unifying all available data

76 sources into a single framework. Integrated population models (IPMs) have been recently

77 developed to infer population demography by making complete use of all available sources of

78 information (see Schaub and Abadi 2011, and Zipkin and Saunders 2018 for reviews). In their

79 simplest form, these models combine population counts and demographic data into a single

80 framework, which allows the estimation of demographic parameters while simultaneously

81 accounting for various sources of uncertainty in each data source (e.g. measurement error or

82 parameter estimation) (Besbeas et al. 2002). The IPM framework has been extended to multiple 
83 species (Péron and Koons 2012) for competition/parasitism, and more recently for predator-prey

84 interactions (Barraquand and Gimenez 2019).

85 Here, our main objective was to quantify the relative contribution of environmental changes and 86 species interactions on demographic parameters of a predator and its prey. Therefore, we used a

87 multispecies IPM framework accommodating the effects of local and global climatic conditions

88 on demographic parameters, such as survival and breeding, while explicitly considering species

89 interactions. We applied our approach on a stage-structured predator-prey system combining 22

90 years of capture-recapture data and population counts on two seabirds, the Brown Skua

91 (Catharacta lönnbergi) and its main prey the Blue Petrel (Halobaena caerulea) ('skua' and

92 'petrel' hereafter) breeding on the Kerguelen Islands in the Southern Ocean.

93 Because seabirds often occupy high level positions in food-webs, bottom-up forcing which

94 implies population regulation through climate driven limitation in food availability, has long

95 been featured as the dominant paradigm to understand their dynamics (Lack 1967, Aebischer et

96 al. 1990, Stenseth et al. 2002). Seabird foraging behavior and demography reflect the influences

97 of climate variability which directly impacts biological processes in marine ecosystems and

98 cascade through food webs up to seabirds (Barbraud and Weimerskirch 2001, Jenouvrier et al.

99 2003). However, top-down pressures from predation at breeding colonies are also known to

100 affect the vital rates of seabirds (Hipfner et al. 2012). There is increasing evidence that bottom-

101 up and top-down processes often act in concert and differently affect demographic parameters

102 (Suryan et al. 2006, Horswill et al. 2014, 2016). For example, the effects of predation and

103 resource limitation caused breeding failure of Black-legged Kittiwakes (Rissa tridactyla)

104 (Regehr and Montevecchi 1997) and population declines of Arctic Skuas (Stercorarius 
parasiticus) (Perkins et al. 2018). Therefore, quantifying the relative strength of environmental

106 conditions and predator-prey effects is essential for a better understanding of the drivers of

107 population dynamics in seabirds. This is all the more important as climate changes impact the

108 physical properties of the oceans, including the Southern Ocean (Gille 2002, Han et al. 2014)

109 and, through the trophic food web, affect demography and population dynamics of seabirds

110 (Barbraud et al. 2012, Sydeman et al. 2015), including some of the species studied here

111 (Barbraud and Weimerskirch 2003).

112 Using a multispecies IPM, we assessed the relative contribution of environment and predator-

113 prey interactions on seabirds' demographic parameters. We estimated survival and adult

114 breeding success for the two interacting species, and assessed the impacts of climatic conditions

115 on these demographic parameters to understand the contribution of predator-prey interactions in

116 shaping population dynamics.

\section{Materials and Methods}

\section{Study site and Species}

119 Skuas and petrels were studied on Mayes Island (49 $\left.28^{\prime} \mathrm{S}, 69^{\circ} 57^{\prime} \mathrm{E}\right)$, a $2.8 \mathrm{~km}^{2}$ uninhabited island

120 of the Kerguelen Islands in the Southern Ocean where the two species breed during the austral

121 summer (October-February).

122 The petrel is a small (150-250g) long-lived seabird belonging to the family of Procellariiformes.

123 At Kerguelen Islands, petrels feed on macrozooplankton and micronekton, mainly crustaceans

124 and fishes (Cherel et al. 2002, 2014). Individuals from Mayes Island spend the nonbreeding 
125 season (from mid-February to September) between the polar front and the northern limit of the

126 pack-ice $\left(57-62^{\circ} \mathrm{S}\right)$ between longitudes $20^{\circ} \mathrm{W}$ and $90^{\circ} \mathrm{E}$ (Cherel et al. 2016). Birds return to

127 breeding colonies in early September (Quillfeldt et al. 2020). Mayes Island is covered with dry

128 soils and dense vegetation, providing suitable breeding sites for approximately 142,000 breeding

129 pairs of these burrowing petrels (Barbraud and Delord 2006). In late October, a single egg is laid

130 in a burrow dug in peat soil under tall and dense vegetation. The incubation lasts $45-49$ days and

131 the chick rearing period 43-60 days (Jouventin et al. 1985). The chick fledges in early February.

132 Both sexes participate in parental care by alternating foraging trips during the incubation and

133 fledging periods.

134 The skua is a medium sized $(1.1-2.2 \mathrm{~kg})$ long-lived seabird belonging to the family of

135 Charadriiformes. On Mayes Island between 80 and 120 pairs breed annually (Mougeot et al.

136 1998). Breeding pairs form in October with a high mate fidelity, and generally establish

137 themselves in the same territory each year (Parmelee and Pietz 1987), which they tenaciously

138 defend throughout the breeding season. Generally, two eggs are laid between October and

139 December. The incubation lasts 28-32 days and the chicks rearing period 40-50 days (Higgins

140 and Davied 1996). Skuas are extremely plastic in their foraging techniques and adapt their diet

141 depending on the local availability of prey (Carneiro et al. 2015). On Mayes Island, during the

142 breeding season, Blue Petrels represent 95\% of the skua diet (Pacoureau et al. 2019c). Skuas

143 from Mayes Island overwinter in the southern hemisphere between $10^{\circ} \mathrm{E}$ and $150^{\circ} \mathrm{E}$ (Delord et

144 al. 2018).

145 During the breeding period on Mayes Island, the predation of petrels by skuas takes place mainly

146 at night, when petrels come out or arrive at their burrows (Mougeot and Bretagnolle 2000a). 
147 Skuas mostly prey on petrels on the ground, but they can also catch petrels in flight (Mougeot et

148 al. 1998, Pacoureau et al. 2019c). Vocalizing petrels, especially those without partners, are more

149 easily detected by skuas during the courtship period (Mougeot and Bretagnolle 2000b). Skuas

150 may also prey on chicks during the fledging period.

\section{Count and capture-recapture data}

152 Data of both skuas and petrels were collected during the breeding seasons from 1996/1997 to

$1532017 / 2018$. For convenience, breeding seasons are named from 1996 to 2017 hereafter. The time

154 interval used in our model starts before the wintering of species and ends at the end of the

155 breeding period. Two types of data were used: count data corresponding to the number of

156 burrows or territories occupied by seabirds and capture-recapture (CR) data of adult seabirds

157 found on the monitored area. Each year, adult individuals of both species were checked at

158 specific times following the species phenology to determine the breeding status of each bird. The

159 breeding status of marked birds was determined at the end of the breeding period. Count data are

160 considered in a post-breeding census. In the following we describe how the data were collected

161 for the two species. For clarity, all parameters for skuas are indicated by $S$ and by $P$ for petrels.

162 Around 200 individually marked burrows of petrels were inspected each year from early-to-mid

163 November just after the egg-laying to check for eggs and to identify marked adults, and then in

164 late January just before fledging of the chicks. Each year since 1985 (see Barbraud and

165 Weimerskirch 2005), all fledglings as well as new individuals found in burrows were marked

166 with a stainless steel band (captured by hand, marked, and replaced in their burrow). Petrels

167 never observed with an egg or a chick during a given breeding season were considered as 
nonbreeders $(N B)$. Individuals were identified as breeders if they laid a single egg or raised a

169 chick and as successful breeders if their chick fledged (SB). Two categories of failed breeders

170 were used depending on the stage of failure: egg stage $(F B E)$ or chick stage $(F B C)$. Given that

171 the first sampling period occurred just after laying, it is very unlikely that nonbreeders were

172 failed breeders. These breeding statuses allowed the construction of the individual capture

173 histories $\left(C h_{P}\right)$ and constituted our $\mathrm{CR}$ data. The annual number of adult petrels $\left(Y_{P}\right)$, i.e. count

174 data, was estimated as the number of occupied burrows. Each occupied burrow was considered

175 as being frequented by a pair of petrels. We considered that this count included all adult

176 individuals, both breeders and non-breeders.

177 For skuas, each year since 1991, the eastern side of Mayes Island was inspected to identify

178 territories of skuas. A territory was considered established when a pair strongly defended an area

179 against other skuas (Mougeot et al. 1998). Around 50 nesting territories were visited four to eight

180 times from mid-October (after egg-laying) to late-February (just before fledging of the chicks)

181 each year. Chicks just before fledging, as well as new adult individuals, were marked with a

182 metal ring and a plastic ring to facilitate individual identification using binoculars. Breeding

183 status was determined by checking the nest contents for the presence of eggs or young chicks.

184 Skuas never observed with an egg or a chick were considered as nonbreeders $(N B)$. Individuals

185 were identified as breeders if they laid at least one egg or raised a chick. If the eggs did not hatch

186 or the chicks died, both members of the pair were considered as failed breeders $(F B)$. Given that

187 the first sampling period occurred just after laying, it is very unlikely that nonbreeders

188 represented failed breeders. Successful breeders were defined as individuals that fledged one or

189 two chicks, and were denoted as $S B 1$ or $S B 2$, respectively. These breeding statuses allowed the 
190 construction of the individual capture histories $\left(C h_{S}\right)$ and constituted our CR data. The annual

191 number of skuas $\left(\mathrm{Y}_{S}\right)$, i.e. count data, was estimated as the number of territories and each

192 territory was considered occupied by a pair of skuas. We considered that this count included all

193 adult individuals, both breeders and non-breeders.

194 For both species, individual breeding status could be considered as "uncertain" $(C)$ in case of 195 difficulties to assign their breeding status (lack of information, missed checks, individuals never 196 re-observed). Only adult individuals that have bred at least once between the 1996 and the 2017 197 breeding seasons were kept in the data set for analysis to eliminate potential transient individuals 198 ( $n=318$ for skuas and $n=1210$ for petrels). Individual capture histories $(\mathrm{Ch})$ started at their first 199 breeding attempt recorded. Based on the high probability of observing breeders in the study site, 200 we assumed that the first breeding attempt was correctly detected. New individuals found in 201 monitored burrows or territories are considered as immigrants to the study site $\left(N_{i m}\right)$.

202 The presence of chicks was used to assign a breeding status to adult individuals captured in the 203 breeding area. In order to maintain the independence of the data, we did not include information 204 on chicks in the model. Therefore, the fecundity was a fixed value. We considered one chick for 205 each pair of seabird, considered as successful breeders $\left(N_{S B, P}\right)$ for petrels or successful breeders 206 with one chick $\left(N_{S B 1, S}\right)$ for skuas $\left(f_{S B, P}\right.$ and $f_{S B 1, S}$ are equal to 1, respectively). For skuas that 207 successfully fledged two chicks $\left(N_{S B 2, S}\right)$, we considered two chicks per pair of skuas $\left(f_{S B 2, S}\right.$ is 208 equal to 2). Since juveniles only return to the breeding sites as adults to attempt to breed for the 209 first time (from four year old or older), we did not have data on juvenile states. 


\section{Integrated Population Model}

211 We built a two-species IPM that combines count and CR data and allows estimating abundances

212 and demographic rates (Besbeas et al. 2002, Schaub and Abadi 2011). More specifically, we

213 connected two IPMs, one for predatory skuas and one for petrels, their main prey, through

214 explicit predator-prey relationships (Barraquand and Gimenez 2019). We incorporated the

215 effects of predation within species-specific vital rates such as survival and breeding parameters.

216 This IPM is structured by states which represent life history states (Fig. 1). We built two

217 likelihoods, one for the CR data and the other for the count data which we combined into a joint

218 likelihood.

219 In the following, we detail the state process following a biological timeline and we explain the

220 different likelihood used. The structure was the same for the two species but states differed in

221 relation to species biology (Fig. 1). The two main differences were: (1) skuas could have up to

222 two chicks versus only one for petrels, (2) the failed-breeder stage in petrels could be split

223 further according to the timing of failure (failure at the incubation vs. chick-rearing stage). For

224 clarity, parameters are indexed by $S$ (for skuas) or $P$ (for petrels) when differences occur, or by $X$

225 (for $S$ or $P$ ) when the structure is the same for both species. We used Poisson $(P o)$ and binomial

226 (Bin) distributions to account for demographic stochasticity. Notations of all parameters and state

227 variables are detailed in Appendix S1: Table S1. 


\section{State process}

\section{Offspring production}

230 The estimated number of skuas and petrels in their first year i.e. between 0 and 1 year old

$231\left(N_{J 1, S, t}\right)$ at year $t$, is modelled with a Poisson distribution:

$232 N_{J 1, S, t} \sim P o\left(0.5 \times f_{S B 1, S} \times N_{S B 1, S, t-1}+0.5 \times f_{S B 2, S} \times N_{S B 2, S, t-1}\right)$

$233 N_{J 1, P, t} \sim \operatorname{Po}\left(0.5 \times f_{S B, P} \times N_{S B, P, t-1}\right)$

234 with $N_{J 1, S}$ the number of chicks produced by all successful skua breeders $\left(N_{S B 1, S}\right.$ and $\left.N_{S B 2, S}\right)$

235 according to their fecundity $\left(f_{S B 1, S}: 1\right.$ chick and $f_{S B 2, S}: 2$ chicks per female skua, sex ratio: 0.5$)$.

236 For petrels, $N_{J 1, P}$ is also Poisson distributed but with only one chick $\left(f_{S B, P}\right)$ per estimated

237 successful female breeder $\left(N_{S B, P}\right.$ with a sex ratio of 0.5$)$.

238 Juvenile survival

239 The number of juveniles between one and two years $\left(N_{J 2}\right)$, two and three years $\left(N_{J 3}\right)$, and three 240 and four years $\left(N_{J 4}\right)$, are modelled with binomial distributions:

$241 \quad N_{J 2, X, t} \sim \operatorname{Bin}\left(\phi_{J 1, X}, N_{J 1, X, t-1}\right)$

$242 N_{J 3, X, t} \sim \operatorname{Bin}\left(\phi_{J 2, X}, N_{J 2, X, t-1}\right)$

$243 \quad N_{J 4, X, t} \sim \operatorname{Bin}\left(\phi_{J 3, X}, N_{J 3, X, t-1}\right)$

244 with the apparent survival between one and two years $\left(\phi_{J 1}\right)$, between two and three years $\left(\phi_{J 2}\right)$

245 and between three and four years $\left(\phi_{J 3}\right)$ respectively. As we observed only adult breeding birds,

246 we had no information on the juvenile phase. We assumed that juvenile apparent survival 12 
247 increased with age (Greig et al. 1983, Grande et al. 2009, Fay et al. 2015), as experienced birds

248 are on average more effective in foraging (Daunt et al. 2007), in competing with conspecifics or

249 in avoiding predators:

$250 \operatorname{logit}\left(\phi_{\text {Jage }_{i}, X}\right)=\lambda_{1, X}+\lambda_{2, X} \times a g e_{i}$

251 where $\phi_{J}$ is the juvenile apparent survival, $a g e_{i}$ the age of the juvenile state (from $N_{J 1}$ to $N_{J 4}$ ),

$252 \lambda_{1}$ the intercept and $\lambda_{2}$ the slope which is constrained to be positive.

\section{Juvenile first breeding attempt}

254 The first breeding attempt in skuas and petrels could start from age four. Four years old

255 individuals and older that did not attempt to breed are in the state $\left(N_{J 4+}\right)$. The individuals that

256 attempted to breed for the first time with a first breeding attempt probability $\operatorname{Pr}$ are in the state

$257 N_{J 4 B}$ and the individuals that did not attempt to breed are in the state $N_{J 4 N B}$ :

$258 N_{J 4 B, X, t} \sim \operatorname{Bin}\left(\operatorname{Pr}_{X, t}, \phi_{J 4, X} \times N_{J 4+, X, t-1}\right)$

$259 \quad N_{J 4 N B, X, t}=\phi_{J 4, X} \times N_{J 4+, X, t-1}-N_{J 4 B, X, t}$

260 with $\phi_{J 4}$ the apparent survival for the $N_{J 4+}$ state. The $N_{J 4+}$ state includes individuals that did not

261 attempt to breed $\left(N_{J 4 N B}\right)$ and individuals aged between three and four years $\left(N_{J 4}\right)$ :

$262 \quad N_{J 4+, X, t}=N_{J 4, X, t}+N_{J 4 N B, X, t}$ 
264 For the two species, we modelled the number of surviving adults $\left(N_{\text {alive }}\right)$ at year $t$ among the 265 total number of adult individuals $\left(N_{\text {adtot }}\right)$ at year $t-1$ with a binomial distribution, with $\phi$ the 266 adult apparent survival:

$267 \quad N_{\text {alive }, X, t} \sim \operatorname{Bin}\left(\phi_{X, t-1}, N_{\text {adtot }, X, t-1}\right)$

268 Breeding probability

269 The number of adult individuals that have bred or not bred among those that survived $\left(N_{\text {alive }}\right)$ is 270 modelled as:

$271 \quad N_{\text {Balive }, X, t} \sim \operatorname{Bin}\left(\beta_{X, t-1}, N_{\text {alive }, X, t}\right)$

$272 N_{N B, X, t}=N_{\text {alive }, X, t}-N_{B a l i v e, X, t}$

273 with $\beta$ the probability of breeding, $N_{\text {Balive }}$ the number of adult breeders that survived and $N_{N B}$

274 the number of adult nonbreeders. As capture histories started at their first breeding attempt

275 recorded, the immigrants, i.e. newly marked individuals $\left(N_{i m}\right)$ coming for the first time in the

276 colony, were considered as breeders. Then, the total number of breeders $\left(N_{B}\right)$ corresponds to the

277 sum of the number of adult breeders that survived $\left(N_{\text {Balive }}\right)$, the number of immigrants $\left(N_{i m}\right)$

278 and the number of juveniles attempting to breed for the first time $\left(N_{J 4 B}\right)$ :

$279 N_{B, X, t}=N_{B a l i v e, X, t}+N_{J 4 B, X, t}+N_{i m, X, t}$ 
281 Breeding success and failure are modelled differently for skuas and petrels. For skuas, the

282 numbers of failed breeders $\left(N_{F B, S}\right)$ and successful breeders $\left(N_{S B, S}\right)$ are modelled following a

283 binomial distribution:

$284 N_{S B, S, t} \sim \operatorname{Bin}\left(\gamma_{S, t-1}, N_{B, S, t}\right)$

$285 \quad N_{F B, S, t}=N_{B, S, t}-N_{S B, S, t}$

286 with $\gamma_{S}$ the probability of a successful breeding. A successful breeder can then have one or two

287 chicks, respectively $N_{S B 1, S}$ and $N_{S B 2, S}$ and this is modelled following a binomial distribution:

$288 N_{S B 2, S, t} \sim \operatorname{Bin}\left(\delta_{S, t-1}, N_{S B, S, t}\right)$

$289 \quad N_{S B 1, S, t}=N_{S B, S, t}-N_{S B 2, S, t}$

290 with $\delta_{s}$ the probability of producing two chicks rather than one among the successful breeders.

291 For petrels, there are two states for failed breeders: one with petrels that failed to hatch their egg

292 (named failed breeder at the egg stage $N_{F B E, P}$ ) and the second with petrels that failed to fledge

293 their chick (named failed breeder at the chick stage $N_{F B C, P}$ ). Hence, there is a parameter of

294 successful hatching $\left(\omega_{P}\right)$. The numbers of petrels with an egg that successfully hatched $\left(N_{S H, P}\right)$

295 and the failed breeders at the egg stage $\left(N_{F B E, P}\right)$ were modelled following a binomial

296 distribution:

$297 N_{S H, P, t} \sim \operatorname{Bin}\left(\omega_{P, t-1}, N_{B, P, t}\right)$

$298 N_{F B E, P, t}=N_{B, P, t}-N_{S H, P, t}$ 
299 with $\omega_{P}$ the probability of successful hatching. Successful breeders $\left(N_{S B, P}\right)$ and failed breeders

300 at the chick stage $\left(N_{F B C, P}\right)$ were modelled following a binomial distribution:

$301 N_{S B, P, t} \sim \operatorname{Bin}\left(\gamma_{P, t-1}, N_{S H, P, t}\right)$

$302 \quad N_{F B C, P, t}=N_{S H, P, t}-N_{S B, P, t}$

303 with $y_{P}$ the probability of successful breeding.

304 Total number of adults

305 For skuas, the total number of adults $\left(N_{\text {adtot }, S}\right)$ corresponds to the sum of adults nonbreeders

$306\left(N_{N B, S}\right)$, failed breeders $\left(N_{F B, S}\right)$, successful breeders with one chick $\left(N_{S B 1, S}\right)$ and successful

307 breeders with two chicks $\left(N_{S B 2, S}\right)$ :

$308 \quad N_{\text {adtot }, S, t}=N_{N B, S, t}+N_{F B, S, t}+N_{S B 1, S, t}+N_{S B 2, S, t}$

309 For petrels, the total number of adults $\left(N_{\text {adtot }, P}\right)$ corresponds to the sum of adults nonbreeders

$310\left(N_{N B, P}\right)$, failed breeders at the egg stage $\left(N_{F B E, P}\right)$, failed breeders at the chick stage $\left(N_{F B C, P}\right)$ and 311 successful breeders $\left(N_{S B, P}\right)$ :

$312 N_{\text {adtot }, P, t}=N_{N B, P, t}+N_{F B E, P, t}+N_{F B C, P, t}+N_{S B, P, t}$

\section{Count data}

314 As only the adult states were observed on the field, we excluded the juvenile states from the

315 observation equation. The observation equation links the observed adult population count $(Y)$

316 (i.e. the number of territories/burrows multiplied by two for a pair of seabird) with the true adult

317 population size $\left(N_{\text {adtot }}\right)$, with an additional term for observation error $(\varepsilon)$ : 
$318 Y_{X, t} \sim \operatorname{Norm}\left(N_{\text {adtot }, X, t}, \varepsilon_{X}\right)$

319 The likelihood for the population count data is denoted

320 as $L_{c o, S}\left(Y_{S} \mid \phi_{J 1, S}, \phi_{J 2, S}, \phi_{J 3, S}, \phi_{J 4, S}, P r_{S}, \phi_{S}, \beta_{S}, \gamma_{S}, \delta_{S}, N_{a d t o t, S}\right)$ for skuas and

321 as $L_{c o, P}\left(Y_{P} \mid \phi_{J 1, P}, \phi_{J 2, P}, \phi_{J 3, P}, \phi_{J 4, P}, P r_{P}, \phi_{P}, \beta_{P}, \omega_{P}, \gamma_{P}, N_{a d t o t, P}\right)$ for petrels.

\section{Capture-recapture data}

323 For adult CR data, we used multievent capture-recapture models to estimate the demographic

324 parameters (Pradel 2005). These models take into account the imperfect detectability of the

325 individuals as well as the uncertainty in the assignment of states to individuals (Gimenez et al.

326 2012).

327 For skuas, our multievent model includes five states: NB, FB, SB1, SB2, dead, and six events:

328 not seen, seen as $\mathrm{NB}$, seen as $\mathrm{FB}$, seen as $\mathrm{SB} 1$, seen as $\mathrm{SB} 2$, seen as $\mathrm{C}$ i.e. individuals seen with

329 an uncertain breeding status. For petrels, the five states are: NB, FBE, FBC, SB, dead, and the

330 six events are: not seen, seen as $\mathrm{NB}$, seen as FBE, seen as FBC, seen as $\mathrm{SB}$, seen as $\mathrm{C}$. The

331 following demographic parameters were estimated for the two species: the adult apparent

332 survival probability $\left(\phi_{X}\right)$, the breeding probability $\left(\beta_{X}\right)$, the probability of successful

333 breeding $\left(\gamma_{X}\right)$. The probability of successful breeding with two chicks $\left(\delta_{S}\right)$ was also estimated

334 for skuas, as well as the probability of hatching $\left(\omega_{P}\right)$ for petrels. Two additional parameters were

335 also estimated: the detection probability $\left(p_{X}\right)$ and the state assignment probability of individuals

336 with uncertain state $\left(u_{X}\right)$. All parameters were time-varying through a yearly random effect,

337 except $u$ (Table 1). State transitions were set to be state dependent according to the breeding

338 status in the previous breeding season (Table 1): Breeder $(\tilde{B})$ representing birds that attempted to 
339 breed the previous breeding season $(F B, S B 1, S B 2$ for skuas or $F B E, F B C, S B$ for petrels) or

340 Nonbreeder $(\widetilde{N B})$ representing birds that already bred previously but did not attempt to breed

341 during the previous breeding season $(N B)$. The detection probability and the state assignment

342 probability also depended on the breeding status (Table 1). The likelihood for the CR data for

343 skuas is denoted as $L_{c r, S}\left(C h_{S} \mid \phi_{S}, \beta_{S}, \gamma_{S}, \delta_{S}, p_{S}, u_{S}\right)$ and $L_{c r, P}\left(C h_{P} \mid \phi_{P}, \beta_{P}, \gamma_{P}, \delta_{P}, p_{P}, u_{P}\right)$ for

344 petrels.

\section{Joint likelihood}

346 The joint likelihood of the skua IPM is the product of the likelihood for the count data $\left(L_{c o, S}\right)$

347 and CR data $\left(L_{c r, S}\right)$ :

$L_{i p m, S}\left(Y_{S}, C h_{S} \mid \phi_{J 1, S}, \phi_{J 2, S}, \phi_{J 3, S}, \phi_{J 4, S}, P r_{S}, \phi_{S}, \beta_{S}, \gamma_{S}, \delta_{S}, N_{a d t o t, S}, p_{S}, u_{S}\right)=$

$L_{c o, S}\left(Y_{S} \mid \phi_{J 1, S}, \phi_{J 2, S}, \phi_{J 3, S}, \phi_{J 4, S}, P r_{S}, \phi_{S}, \beta_{S}, \gamma_{S}, \delta_{S}, N_{a d t o t, S}\right) \times$

350

$L_{c r, S}\left(C h_{S} \mid \phi_{S}, \beta_{S}, \gamma_{S}, \delta_{S}, p_{S}, u_{S}\right)$

351 For petrels, the product of the likelihood for the count data $\left(L_{c o, P}\right)$ and CR data $\left(L_{c r, P}\right)$ is

denoted as: $L_{i p m, P}\left(Y_{P}, C h_{P} \mid \phi_{J 1, P}, \phi_{J 2, P}, \phi_{J 3, P}, \phi_{J 4, P}, P r_{P}, \phi_{P}, \beta_{P}, \omega_{P}, \gamma_{P}, N_{\text {adtot }, P}, p_{P}, u_{P}\right)$.

\section{Interspecific relationships, intraspecific density-dependence, and environmental}

\section{4 covariates}

355 We used different covariates to investigate their effects on the adult demographic parameters

356 estimated for the two species (Table 2). We focused only on the demographic parameters of adult

357 individuals because only adults were observed on the field. We tested interspecific predator-prey

358 relationships between skua and petrel, and intraspecific relationships with density-dependence 18 
359 for both species. Moreover, we considered several climatic covariates that were suspected to

360 affect demographic parameters of skuas and petrels, the Southern Annular Mode (SAM) on a

361 large scale, and the Sea Surface Temperature anomalies (SSTa) and Chlorophyll a concentration

362 (Chla) on a local scale. In the following, we provide more details on covariates and how they

363 may affect the demography of skuas and petrels.

\section{Predator-prey interactions}

365 Multispecies IPMs allow us to explicitly include interspecific relationships between vital rates of

366 one species and estimated population sizes of the other. Based on the high proportion of petrels

367 in the diet of the skuas during the breeding season (Mougeot et al. 1998, Pacoureau et al. 2019c),

368 we predicted that petrel adult apparent survival $\left(\phi_{P}\right)$ should decrease with the number of skuas.

369 As skuas prey on adults and chicks during the fledging period, we predicted that the hatching

370 success $\left(\omega_{P}\right)$ and fledging success $\left(\gamma_{P}\right)$ would be impacted by the number of predators.

371 Inversely, we predicted that a large number of petrels in the breeding colony would provide

372 enough food resources for skua and then be favorable to their breeding success $\left(\gamma_{S}\right)$ and breeding

373 success with two chicks $\left(\delta_{S}\right)$.

\section{Intraspecific density-dependence}

375 We investigated the effect of intraspecific density-dependence on the demography of the two

376 species as higher density of individuals on the breeding area can lead to and an increasing

377 competition for food resources or for territories. Skuas are highly territorial and defend their

378 territories vigorously during the whole breeding season. The most violent fights may even lead to

379 their death. Moreover, the limited number of territories could cause emigration of skuas without 
380 territory. Thus, we predicted that the apparent survival $\left(\phi_{S}\right)$, i.e. the joint estimation of the

381 mortality and emigration, would be negatively impacted by the number of skuas. This limited

382 number of territories could also lead to a negative density-dependence relationship between

383 breeding probability $\left(\beta_{S}\right)$ and population density. The energetic cost and the time spent in

384 defending a territory throughout the breeding season may limit the time spent searching for food,

385 potentially limiting energy investment in reproduction. We thus predicted a negative effect of

386 population density on the successful breeding parameter $\left(\gamma_{S}\right)$ and the probability to have two

387 chicks rather than one for successful breeders $\left(\delta_{S}\right)$. For petrels, we also tested the effects of

388 intraspecific competition for food resources, which could affect their adult apparent survival

$389\left(\phi_{P}\right)$ and their breeding parameters: breeding probability $\left(\beta_{P}\right)$, hatching $\left(\omega_{P}\right)$ and fledging

$390 \operatorname{success}\left(\gamma_{P}\right)$.

\section{Environmental covariates}

392 Climate variability impacts biological processes in marine ecosystems, which cascade through

393 food webs and are integrated by seabirds (Barbraud and Weimerskirch 2001, Jenouvrier et al.

394 2003). Hence, we considered several covariates that are suspected to affect populations of petrels

395 and skuas through these bottom-up mechanisms. All covariates are used as proxies of food

396 availability at sea at different scales. In the following, we explain how environmental conditions

397 may impact the two species based on their diet and distribution.

398 Because skuas have broad wintering areas (Delord et al. 2018), we tested a large-scale

399 environmental covariate, the SAM. In contrast with their diet during the breeding season

400 specialized on the Blue Petrel, during winter skuas adopt a mixed diet composed of low trophic

401 level preys, such as macrozooplankton and crustaceans (Delord et al. 2018). We hypothesized 20 
402 that availability of food resources at sea during the austral winter might have an effect on the

403 body condition of skuas and then affect the survival of skuas. Moreover, skuas may experience a

404 carry-over effect as the additional energy invested by individuals to maintain themselves during

405 poor wintering conditions may have repercussion on their ability to breed the next breeding

406 season (Harrison et al. 2011, Bogdanova et al. 2017)

407 For petrels, the wintering areas have been determined (Cherel et al. 2016) allowing us to test two

408 covariates used at the local scale, the SSTa and the Chla, in addition to the SAM. As their diet is

409 mainly composed of crustaceans and fish feeding at low trophic levels (Cherel et al. 2002, 2014),

410 the food availability at sea may impact the survival of petrels. Moreover, during the breeding

411 season, male and female petrels take turns, one incubating the egg and fasting and the other

412 foraging at sea, which results in substantial variation in their body mass (Chaurand and

413 Weimerskirch 1994a, 1994b, Weimerskirch et al. 1994, Chastel et al. 1995). Therefore, high

414 food availability at sea may allow a good foraging success of the foraging partner that may return

415 to land after a short stay at sea, allowing a good synchronization of the breeding partners on the

416 nest. In contrast, poor conditions could increase the time spent at sea by the foraging partner,

417 which would increase desertion of the nest by the fasting partner and then, reduce the breeding

418 success. We thus predicted that conditions at sea during the breeding season would also affect

419 the breeding success of petrels.

\section{Southern Annular Mode}

421 The SAM is a large-scale climate index. SAM is the leading mode of climate variability over the

422 Southern Hemisphere. SAM is defined as the difference of atmospheric pressure between the

$42340^{\circ} \mathrm{S}$ and $65^{\circ} \mathrm{S}$ latitudes (Marshall 2003). SAM influences surface wind, sea surface temperature 21 
424 (SST) and surface chlorophyll concentration. A large majority of the skuas from Mayes Island

425 overwinter north of the polar front (Delord et al. 2018). In the subtropical zone, SAM positive

426 phases induced warm SSTa, low surface chlorophyll concentration and easterly winds driving

427 Ekman transport (the $90^{\circ}$ wind-driven net transport on the sea surface), while in the Subantarctic

428 zone there is a convergence of waters that increase downwelling and positive SSTa (Lovenduski

429 and Gruber 2005). We thus predicted that the positive phases of SAM, potentially leading to

430 poorer food availability in the areas used by skuas during the nonbreeding period, would have

431 negative impacts on skua survival and limit their ability to breed the next breeding season. South

432 of the polar front, where petrels spend the winter, positive phases of the SAM are associated with

433 westerly winds. This induces cold SSTa, increased equatorward Ekman transport and drives

434 increased upwelling (Lovenduski and Gruber 2005). Consequently, the biological productivity

435 and potential prey availability for petrels are higher during positive phases of the SAM. We thus

436 predicted that the positive phases of SAM would be favorable for petrel demographic

437 parameters. Data were obtained from the online database of the British Antarctic Survey

438 (http://www.nerc-bas.ac.uk/ icd/gjma/sam.html).

\section{Sea Surface Temperature anomalies}

440 SSTa reflect local oceanographic conditions that influence the whole marine trophic food web.

441 High SST generally reduces vertical mixing and provides poor growing conditions for

442 zooplankton communities which, through bottom-up mechanisms, induces reduced trophic

443 resources for seabirds (Barbraud et al. 2012, Sydeman et al. 2015). Consequently, year-to-year

444 variation of SST was previously found to be negatively correlated with petrel body condition

445 (Guinet et al. 1998). Therefore, we predicted that high SSTa would negatively affect overwinter 
446 survival and breeding success of petrels. The SSTa data were downloaded from the National

447 Oceanic and Atmospheric Administration (“data: NOAA NCEP EMC CMB GLOBAL

448 Reyn_SmithOIv2 monthly ssta”) from 1996 to 2018.

449 Chlorophyll a

450 Chlorophyll a lies at the bottom of the marine food web and provides resources for higher trophic

451 organisms up to seabirds. Because petrel diet is mainly composed of crustaceans and fish feeding

452 at low trophic levels (Cherel et al. 2002, 2014), we predicted that high concentrations of Chla

453 would be favorable to the survival and breeding success of petrels. The Chla data were

454 downloaded from the NASA Ocean Data with a 9km mapped concentration data of chlorophyll a

455 for the years 1997 to 2001 and from the Nasa Earth Observation (NEO AQUA/MODIS data)

456 monthly for the years 2002 to 2018 .

457 Assessing the effect of environmental covariates and population densities

458 We fitted a single multispecies IPM including all the biologically relevant effects. Logit-linear

459 regressions were used to estimate the effect of environmental (SAM, SSTa and Chla) and inter-

460 and intra-specific interactions on demographic parameters (adult apparent survival, breeding

461 probability, hatching probability, breeding success) (Table 2). We used state variables

$462 N_{\text {adtot }, S}$ and $N_{\text {adtot }, P}$, respectively the number of adult skuas and petrels, to assess the effects of

463 inter- and intra-specific interactions. For example, we modelled the hatching probability for

464 petrels that bred the previous year $\left(\omega_{P, \tilde{B}}\right)$ using a logit link:

$465 \operatorname{logit}\left(\omega_{P, \tilde{B}, t-1}\right)=\mu_{\omega, P, \tilde{B}}+\alpha_{S A M, \omega, P, \tilde{B}} \times S A M_{\omega, P, t}+\alpha_{S S T a, \omega, P, \tilde{B}} \times S S T a_{\omega, P, t}+$

$466 \alpha_{C h l a, \omega, P, \tilde{B}} \times \operatorname{Chla}_{\omega, P, t}+\alpha_{D D, \omega, P, \tilde{B}} \times N_{\text {adtot }, P, t}+\alpha_{P P, \omega, P, \tilde{B}} \times N_{\text {adtot }, S, t}+\varepsilon_{\omega, P, \tilde{B}, t}$ 
468 with $\mu_{\omega, P, \tilde{B}}$ the intercept, $\alpha_{S A M_{\omega, P, \widetilde{B}}}$ the slope for the climatic covariate $S A M_{\omega, P}, \alpha_{S S T a, \omega, P, \tilde{B}}$ the

469 slope for the climatic covariate $S S T a_{\omega, P}, \alpha_{C h l a, \omega, P, \tilde{B}}$ the slope for the climatic covariate $C h l a_{\omega, P}$,

$470 \alpha_{D D, \omega, P, \tilde{B}}$ the slope indicating the strength of the intraspecific density-dependence with

$471 N_{\text {adtot,P}}$ the number of adult petrels, $\alpha_{P P, \omega, P, \tilde{B}}$ the slope indicating the strength of the predator-

472 prey relationship with $N_{a d t o t, S}$ the number of adult skuas, $\varepsilon_{\omega, P, \tilde{B}}$ is a yearly random effect and

$473 \sigma_{\varepsilon, \omega, P, \tilde{B}}^{2}$ its temporal variance. This temporal random effect allows to capture residual

474 environmental stochasticity that is not explained by temporal covariates. The descriptions of all

475 logit-linear relationships used on demographic parameters are available in Appendix S2 and the

476 temporal used of covariates is described in Appendix S3: Fig. S1.

477 For local covariates (SSTa and Chla), we calculated the average values of the covariates in the

478 areas in which petrels were located (Cherel et al. 2016) in a specific time period during which the

479 environment might affect the demographic parameter under investigation (Table 2). Each

480 environmental covariate was standardized to have zero mean and unit variance. However, the

481 inter- and intra-specific covariates were not standardized prior to the analyses because the

482 population sizes were estimated step by step each year. To compare the relative contribution of

483 the effects of each covariate, we calculated the standardized effect of population size (for inter-

484 and intra-specific relationship) posterior to the analyses by multiplying their slopes $(\alpha)$ by the

485 standard deviation of the estimated population sizes. Then, we compared the relative contribution

486 of each covariate using the regression estimate which we used as a measure of effect size. 
487 We computed the $95 \%$ and $80 \%$ credible intervals (CRI) for the regression coefficients $\alpha$. We 488 did not interpret uncertain effects (i.e. 80\% CRI including zero) and focused particularly on clear 489 effects whose sign could be reliably assessed (i.e. 95\% CRI excluding zero).

\section{Model implementation}

491 To fit the juvenile apparent survival parameters increasing with age, we modelled them as a 492 positive linear function of age by assigning to the slope $\lambda_{2}$ a $U(0,1)$ prior, and by defining the 493 intercept $\lambda_{1}$ with a normal $N(0,1)$ prior. The probability of the first breeding attempt $(\mathrm{Pr})$ is

494 time-dependent with a uniform prior: $P r_{t} \sim \mathrm{U}(0,1)$. Normal priors $N\left(0,10^{4}\right)$ were assigned to the 495 regression coefficients $(\alpha)$ of the covariate effects. For the variance of the random year 496 effects $\left(\sigma_{\varepsilon}^{2}\right)$, we used a $U(0,10)$ vague prior. The state assignment probability of individuals 497 with uncertain state parameter $(u)$ was defined a priori with a $U(0,10)$ vague prior.

498 Bayesian posterior distributions were approximated via Markov chain Monte Carlo (MCMC) 499 algorithms. Two independent MCMC chains of 200,000 iterations were used with a burn-in 500 period of 100,000. One out of five iterations was kept and final inferences were derived from a 501 sample of $2 \times 20,000$ iterations that resulted from merging the two chains. Gelman-Rubin 502 convergence diagnostic (Brooks and Gelman 1998) was below 1.5 for each parameter and the 503 mixing of the chains was satisfactory. We performed the analyses using Nimble (de Valpine et 504 al. 2017 ; version 0.9.1) and program R (R Core Team 2020 ; R version 4.0.3). Code and data are 505 available on GitHub at https://github.com/maudqueroue/MultispeciesIPM_SkuaPetrel. 


\section{Results}

\section{Predator-prey relationships}

508 We estimated positive relationships between two breeding parameters of skuas and the number

509 of adult petrels. The breeding success for at least one chick $\left(\gamma_{S, \tilde{B}}\right)\left[\right.$ slope mean $\left(\alpha_{P P}{ }_{\gamma, S, \widetilde{B}}\right)=0.67$;

$51095 \%$ CRI $(0.38,1.04)]$ (Fig. $2 \mathrm{a})$ and the breeding success with two chicks $\left(\delta_{S, \tilde{B}}\right)$ [slope mean

$511\left(\alpha_{P P_{\delta, S, \widetilde{B}}}\right)=1.28 ; 95 \%$ CRI $\left.(0.67,2.08)\right]$ (Fig. 2b) for skuas that were breeders the previous

512 breeding season increased with an increasing number of prey. Even though the effects were less

513 clear (95\% CRI including zero), the breeding success and survival of petrels tended to be

514 positively impacted by the number of predators (Table 3). We detected a positive relationship

515 between the number of adult skuas and the hatching success of petrels that were breeders the

516 previous breeding season $\left(\omega_{P, \tilde{B}}\right)$, with the breeding success $\left(\gamma_{P, \widetilde{N B}}\right)$ and with the apparent

517 survival $\left(\phi_{P, \widetilde{N B}}\right)$ of petrels that were nonbreeders the previous breeding season. We found no

518 other interspecific relationship on the other parameters (Table 3).

\section{Intraspecific density-dependence}

520 The number of skuas had a clear effect on two demographic parameters, namely the breeding

521 success and the breeding success with two chicks for skuas that were breeders the previous

522 breeding season. We found negative density-dependence for the breeding success $\left(\gamma_{S, \tilde{B}}\right)[$ slope

523 mean $\left(\alpha_{D D_{\gamma, S, \widetilde{B}}}\right)=-0.40 ; 95 \%$ CRI $\left.(-0.66,-0.15)\right]$ (Fig. 2c) and for the probability of producing

524 two chicks rather than one $\left(\delta_{S, \tilde{B}}\right)$ [slope mean $\left(\alpha_{D D_{\delta, S, \widetilde{B}}}\right)=-0.54 ; 95 \%$ CRI $\left.(-1.04,-0.13)\right]($ Fig. 
$5252 \mathrm{~d})$. These two breeding parameters were also affected by interspecific relationships and we

526 observed that the predator-prey effects were stronger than intraspecific effects $\left(\left|\operatorname{mean} \alpha_{P P_{\gamma, S, \widetilde{B}}}\right|=\right.$

$5270.67 ; \mid$ mean $\alpha_{D D_{\gamma, S, \widetilde{B}}} \mid=0.40$ respectively) for the breeding success and $\left(\mid\right.$ mean $\alpha_{P P_{\delta, S, \widetilde{B}}} \mid=1.28$;

$528 \mid$ mean $\alpha_{D D_{\delta, S, \widetilde{B}}} \mid=0.54$ respectively) for the breeding success with two chicks (Table 3).

529 For petrels, we estimated a positive effect of increased number of adult petrels on the breeding

530 probability for individuals that were breeders the previous breeding season $\left(\beta_{P, \tilde{B}}\right)$ [slope

531 mean $\left(\alpha_{D D_{\beta, P, \widetilde{B}}}\right)=0.65 ; 95 \%$ CRI $\left.(0.19,1.06)\right]$ (Fig. 2e). Even though the effects were less clear

532 (95\% CRI including zero), the number of petrels tended to negatively affect the apparent survival

$533\left(\phi_{P, \widetilde{N B}}\right)$ and the breeding success $\left(\gamma_{P, \widetilde{N B}}\right)$ of petrels that did not bred the previous breeding

534 season (Table 3).

\section{Environmental covariates}

536 We found ecologically relevant relationships between environmental covariates and

537 demographic parameters of the two species (Table 3). For petrels, we found positive

538 relationships between the two local environmental covariates (SSTa and Chla) and the breeding

539 probability for individuals that were nonbreeders the previous breeding season $\left(\beta_{P, \widetilde{N B}}\right)$. The

540 effect of these environmental covariates on the breeding probability was stronger for the Chla

541 covariate than for the SSTa covariate $\left(\mid\right.$ mean $\alpha_{C h l a_{\beta, P, \widetilde{N B}}}|=0.78 ;|$ mean $\alpha_{S S T a_{\beta, P, \widetilde{N B}}} \mid=0.31$

542 respectively). We estimated a positive relationship between the SAM covariate and the hatching

543 success $\left(\omega_{P, \tilde{B}}\right)$ and breeding success $\left(\gamma_{P, \tilde{B}}\right)$ of petrels that were breeders the previous breeding

544 season and with the hatching success $\left(\omega_{P, \widetilde{N B}}\right)$ of petrels that were nonbreeders the previous 27 
545 breeding season. For skuas, we also found a positive relationship between the SAM and the

546 breeding probability $\left(\beta_{S, \widetilde{N B}}\right)$ of skuas that were nonbreeders the previous breeding season.

547 In addition to the results above, we also estimated the demographic parameters and the number

548 of individuals in each state for both species from 1996 to 2017 (see Appendix S4: Figs. S1- S6).

\section{Discussion}

550 In this paper, we provide the first application of a multispecies IPM in a predator-prey context.

551 Joint analysis of empirical data for two seabird species allowed us to estimate demographic

552 parameters and population size for both simultaneously. The key advantage of using a

553 multispecies IPM was that it enabled us to use the population sizes estimated by the model for

554 one species to analyze its effect on the demographic parameters of the other species while

555 propagating all sources of uncertainty. Hence, it allowed us to understand the contribution of

556 interspecific interactions on the demographic parameters while further taking into account the

557 effects of climatic conditions. Our results showed that the demography of the predatory skua was

558 mainly driven by the number of petrel prey during the breeding season whereas petrels were

559 mostly impacted by the environment. This suggests that this predator-prey system is mainly

560 driven by bottom-up processes and density-dependent processes.

\section{Effects of predator-prey relationships}

562 The number of prey is a determining factor in the breeding success of skuas according to our

563 results. Food availability is known to be positively related with breeding parameters in seabirds

564 (Cairns 1988, Piatt et al. 2007, Oro et al. 2014). As diet of skuas during the breeding period is 
565 dominated by petrels (Mougeot et al. 1998, Pacoureau et al. 2019c), a large abundance of petrels

566 provides easier conditions for skuas to feed themselves and their chicks resulting in a higher

567 breeding success.

568 Interestingly, we did not find the opposite relationship in the prey dynamics. Our model provided

569 no evidence for a negative effect of the number of skuas on the demographic parameters of the

570 petrel. As skuas prey on both adults and juveniles during the breeding season, we expected a

571 negative effect of the number of skuas on the petrel breeding parameters. This lack of effect

572 could be explained by the large abundance of petrels compared to the skuas on Mayes Island.

573 Oro et al. (2006) reported that in another seabird predator-prey system, the highest breeding

574 success of the prey occurred when the prey/predator ratio was very high. On Mayes Island, the

575 breeding population of petrels is estimated at approximately 142,000 breeding pairs (Barbraud

576 and Delord 2006), and this does not include chicks (around 71,000 each year) and nonbreeders

577 (approximately 30\% of the petrels). Hence, there are about 476,000 petrels during a breeding

578 season versus about 200 skuas, resulting in a very high prey/predator ratio. Moreover, Mougeot

579 et al. (1998) showed that skuas breeding at Mayes Island preyed on about 40,000 petrels each

580 breeding season. This corresponds to about $8 \%$ of the petrel population of the island. It is

581 therefore possible that skua predation is only a minor factor in shaping petrel demographics, and

582 this effect may be too weak to be detected by our model. Inversely, although the relationships

583 estimated were less clear, our results suggest that the density of skuas tended to increase slightly

584 with the hatching success and breeding success of the prey. However, it is unlikely that the

585 presence of predators increased the reproductive success or survival of petrels. To explain these

586 relationships, we might rely on the other strong effects estimated by our model. Indeed, we found 
587 that the number of petrels positively affected the breeding success of skuas and that skuas were

588 sensitive to intraspecific density-dependence. Therefore, years when prey experience a high

589 survival and breeding success correspond to years with particularly abundant food resources for

590 skuas and this until the end of the breeding season as petrels stay longer on the breeding area

591 when they successfully breed. Since skuas are potentially less affected by intraspecific density-

592 dependence than by abundance of prey, they could potentially breed in higher numbers in the

593 breeding area.

\section{Effects of intraspecific density-dependence}

595 For skuas, we found negative density-dependent effects on breeding success and probability to

596 fledge two chicks, in accordance with our predictions. Egg and chick predation by conspecifics

597 has been reported in the Great Skua (Catharacta skua) (Hamer et al. 1991, Ratcliffe and Furness

598 1999). Hence, a higher abundance of skuas increases the risk of predation on eggs and chicks,

599 resulting in higher breeding failure. To avoid predation by conspecifics, the skuas start defending

600 their territories from conspecifics just a few days after arrival on a breeding site until the end of

601 the season. This activity is energetically costly and may also limit the time spent searching for

602 food, potentially limiting energy investment in reproduction. The heterogeneous habitat

603 hypothesis already demonstrated in territorial birds (Dhondt et al. 1992, Krüger and Lindström

604 2001, Ferrer and Donazar 2015) could also explain the relationships we found. Indeed, when the

605 population increases, some individuals may be forced to occupy poorer quality habitats, resulting

606 in lower reproductive success. We did not find an effect of density-dependence on the breeding

607 probability of skuas. As skuas are territorial with high site fidelity, we hypothesized that in years

608 with a high abundance of skuas, the breeding probability would decrease, as all the skuas would 30 
not succeed in acquiring a territory. It is possible that we did not observe this effect because the

610 logistic function used for density-dependence does not accurately model the territory acquisition

611 dynamics by floaters (e.g. van de Pol et al. 2010, Barraquand et al. 2014).

612 We estimated that the breeding success of skuas was affected by both predator-prey relationships

613 and intraspecific density-dependence. Predator-prey relationships had a higher contribution to

614 the variability in breeding success of skuas than the density-dependent effect. Hamer et al.

615 (1991) reported that, following a reduction of sandeel (Ammodytes marinus) abundance, great

616 skua increased their foraging effort reducing the adult territorial attendance. In turn, breeding

617 failure increased due to predation from adults of neighboring territories. We then may assume

618 that petrel abundance allowed a suitable territorial attendance for skuas reducing the negative

619 density-dependent effects such as chick predation by conspecifics.

620 For petrels, we found a negative relationship between the survival and breeding success of petrel

621 that did not breed the previous year and the number of petrels on the colony. Combined effects of

622 density-dependence and climate have already been observed in petrels, with a lower winter

623 survival when density is high (Barbraud and Weimerskirch 2003), suggesting a mechanism of

624 competition between conspecifics for food resources. As nonbreeders are known to be in poorer

625 condition than breeders (Chastel et al. 1995), they are potentially more sensitive to the

626 competition for food resources explaining why this effect was only found on petrels that were

627 nonbreeders the previous years. Interestingly, we found a positive intraspecific density-

628 dependence relationship on the breeding probability of petrels that bred the previous year. This

629 suggests that years with a high abundance of petrels reflected a good return rate to the breeding

630 site because environmental conditions were favorable for breeding. This is in agreement with 31 
631 studies showing that petrels might skip breeding and take sabbatical years when environmental

632 conditions are poor (Warham 1990, Chastel et al. 1995).

\section{Effects of environmental conditions}

634 We detected positive relationships between the hatching and breeding success of petrels and the

635 SAM covariate. South of the polar front, where petrels feed during the breeding season, positive

636 phases of the SAM increase the biological productivity and potential prey availability for petrels

637 (Lovenduski and Gruber 2005) which may have a positive impact on their breeding success.

638 Breeding probability of petrels tended to be impacted by two of the environmental covariates

639 tested, namely SSTa and Chla. This effect of environmental conditions on the breeding

640 probability is in accordance with previous research showing that the body condition of petrels

641 might impact their decision to attempt breeding (Warham 1990, Chastel et al. 1995). High Chla

642 increases resources availability for organisms at higher trophic levels (macrozooplankton,

643 fishes), which are consumed by petrels (Cherel et al. 2002). Consequently, high Chla may

644 increase abundance of petrel prey, with a positive effect on the breeding performances and body

645 condition of petrels. Unexpectedly, we detected a positive effect of SSTa on breeding probability

646 of petrels. This result is surprising as a previous study showed that warm SST events negatively

647 affected the breeding performances and body condition of petrels at Kerguelen Islands (Guinet et

648 al. 1998). Indeed, high SST generally reduces vertical mixing and provides poor growing

649 conditions for zooplankton communities that in turn reduce trophic resources for seabirds

650 (Barbraud et al. 2012, Sydeman et al. 2015). However, it has been showed recently that during

651 the pre-laying period petrels use water masses situated at more northerly latitudes than during the

652 winter period or the breeding period (Quillfeldt et al. 2020), where relationships between SST 32 
653 and primary productivity may differ. Indeed, the covariance between SST and Chla depends on

654 location and shows particularly complex patterns in the Southern Ocean (Dunstan et al. 2018).

655 Positive effects of SSTa have already been identified in other subantarctic seabirds (Pinaud and

656 Weimerskirch 2002, Nevoux et al. 2007, Horswill et al. 2014). Furthermore, we estimated that

657 Chla, at the bottom of the trophic food chain, had a higher effect on the breeding probability than

658 SSTa which reflect oceanographic conditions. This indicated that the effect size of

659 environmental covariates increased when the covariates approached the trophic level occupied

660 by the prey of the petrels, suggesting a bottom-up mechanism. This result is consistent with

661 many studies showing that climatic conditions affect seabirds through indirect processes by

662 influencing prey availability and resulting in changes in their dynamics (Frederiksen et al. 2006,

663 Barbraud et al. 2012, Jenouvrier 2013, Lauria et al. 2013).

664 We did not detect any relationship between the breeding success of the skua and the

665 environmental covariates. This lack of effect could be explained by an absence of a direct link

666 between skuas and the environmental covariates tested, as breeding skuas remain on their

667 territory to defend it or to forage. However, we found an effect of SAM on the breeding

668 probability for skuas that were nonbreeders during the previous season. It was proposed that only

669 seabirds attaining a threshold condition decide to breed (Weimerskirch 1992). Therefore,

670 environmental conditions before the breeding period may impact the conditions of skuas and

671 consequently, their breeding decision. Nonbreeders are generally in poorer conditions than

672 breeders (Chastel et al. 1995, Cam et al. 1998) and thus more sensitive to environmental

673 conditions explaining why this effect is only detected on previous nonbreeders. Nevertheless, we

674 found a positive relationship between breeding probability and SAM whereas we expected a 
675 negative relationship. Indeed, skuas mainly overwinter north of the polar front (Delord et al.

676 2018) where positive phases of SAM induce warm SST, low surface Chla concentration

677 (Lovenduski and Gruber 2005), and thus potentially poor feeding conditions. However, only

678 breeding skuas were studied in Delord et al. (2018) and nonbreeding individuals may use

679 different wintering areas where the relationships between SAM and oceanographic variables

680 differ. Several studies reviewed in Jenouvrier (2013) highlighted multifaceted effects of climatic

681 conditions on the demography of seabirds involving direct, time-lagged and non-linear effect,

682 which we did not consider here. Therefore, despite the important contribution of our approach in

683 understanding the effect of the environment in our predator-prey system, disentangling the

684 complex mechanisms between environmental covariates and their effects on the demography of

685 the two seabirds remains challenging.

686 A bottom-up dynamic in a predator-prey system

687 Overall, our study has highlighted the important role of bottom-up processes in the dynamics of 688 this marine predator-prey system, i.e. the dynamics of these two seabirds was mostly driven by

689 food availability. Petrel dynamics were more strongly affected by environmental covariates and

690 the number of petrels impacted the dynamics of skuas. The bottom-up control of demographic

691 rates in oceanic predators have been largely assumed (Jenouvrier 2013). This is because the

692 functioning of oceanic systems is controlled and structured by physical processes impacting

693 nutrient fluxes (Behrenfeld et al. 2006) and then the whole trophic food web. We found no

694 evidence of top-down processes, i.e. predation effects, in this system, although these two

695 mechanisms have been found to jointly affect ecosystems (Hunter and Price 1992, Sinclair et al.

696 2003) including other seabird systems (Horswill et al. 2014, 2016, Perkins et al. 2018). Effects of 34 
697 skua predation on petrels were expected, based on their diet during the breeding season.

698 However, given the very large number of petrels present on the island compared to the number

699 of predators, the impact of predation may have been too small to be detected by our model.

\section{Conclusion}

701 This multispecies IPM framework allowed us to estimate demographic parameters and

702 abundances for both skuas and petrels. Taking into account both species interactions and

703 environmental covariates in the same analysis improved our understanding of species dynamics.

704 We concluded that bottom-up mechanisms are the main drivers of this skua-petrel system.

705 Generalizing such assessments of interspecific relationships and environmental conditions in a

706 single demographic framework may be essential to predict how contrasted climatic scenarios will

707 affect communities. A promising avenue of research in multispecies IPMs lies in fitting models

708 to data on a large number of species, which will likely require further methodological

709 developments.

\section{Acknowledgments}

711 This study was made possible thanks to all the field workers involved in the monitoring

712 programs on Brown Skuas and Blue Petrels since 1985 at Mayes Island, Kerguelen Islands.

713 These monitoring programs were supported financially and logistically by the French Polar

714 Institute IPEV (program 109, resp. Henri Weimerskirch), the Zone Atelier Antarctique (CNRS-

715 INEE), Terres Australes et Antarctiques Françaises. All work was carried out in accordance with

716 the guidelines of the IPEV ethics committee. We thank Chloé R. Nater for constructive feedback

717 and helpful suggestions on the manuscript. We acknowledge Dominique Joubert for the 35 
718 management of the demographic database. We thank Dave Koons and Matthew Farr for useful

719 comments that helped improved a previous version of the manuscript. This research was funded

720 by the French National Research Agency (grant ANR-16-CE02-0007).

\section{$721 \quad$ Literature Cited}

722 Aebischer, N. J., J. C. Coulson, and J. M. Colebrookl. 1990. Parallel long-term trends across four 723 marine trophic levels and weather. Nature 347:753-755.

724 Barbraud, C., and K. Delord. 2006. Population census of blue petrels Halobaena caerulea at 725 Mayes Island, Iles Kerguelen. Antarctic Science 18:199-204.

726 Barbraud, C., V. Rolland, S. Jenouvrier, M. Nevoux, K. Delord, and H. Weimerskirch. 2012.

727 Effects of climate change and fisheries bycatch on Southern Ocean seabirds: a review. Marine $728 \quad$ Ecology Progress Series 454:285-307.

729 Barbraud, C., and H. Weimerskirch. 2001. Emperor penguins and climate change. Nature $730 \quad 411: 183-186$.

731 Barbraud, C., and H. Weimerskirch. 2003. Climate and density shape population dynamics of a 732 marine top predator. Proceedings of the Royal Society B: Biological Sciences 270:21117332116.

734 Barbraud, C., and H. Weimerskirch. 2005. Environmental Conditions and Breeding Experience 735 Affect Costs of Reproduction in Blue Petrels. Ecology 86:682-692.

736 Barraquand, F., and O. Gimenez. 2019. Integrating multiple data sources to fit matrix population 737 models for interacting species. Ecological Modelling 411. 
738 Barraquand, F., T. T. Høye, J.-A. Henden, N. G. Yoccoz, O. Gilg, N. M. Schmidt, B. Sittler, and 739 R. A. Ims. 2014. Demographic responses of a site-faithful and territorial predator to its 740 fluctuating prey: long-tailed skuas and arctic lemmings. Journal of Animal Ecology 83:375741 387.

742

743

744

745

746

747

748

749

750

751

752

753

754

755

756

757

758

Behrenfeld, M. J., R. T. O’Malley, D. A. Siegel, C. R. McClain, J. L. Sarmiento, G. C. Feldman, A. J. Milligan, P. G. Falkowski, R. M. Letelier, and E. S. Boss. 2006. Climate-driven trends in contemporary ocean productivity. Nature 444:752-755.

Besbeas, P., S. N. Freeman, B. J. T. Morgan, and E. A. Catchpole. 2002. Integrating MarkRecapture-Recovery and Census Data to Estimate Animal Abundance and Demographic Parameters. Biometrics 58:540-547.

Bogdanova, M. I., A. Butler, S. Wanless, B. Moe, T. Anker-Nilssen, M. Frederiksen, T. Boulinier, L. S. Chivers, S. Christensen-Dalsgaard, S. Descamps, M. P. Harris, M. Newell, B. Olsen, R. A. Phillips, D. Shaw, H. Steen, H. Strøm, T. L. Thórarinsson, and F. Daunt. 2017. Multicolony tracking reveals spatio-Temporal variation in carry-over effects between breeding success and winter movements in a pelagic seabird. Marine Ecology Progress Series 578:167181.

Brooks, S. P., and A. Gelman. 1998. General Methods for Monitoring Convergence of Iterative Simulations. Journal of Computational and Graphical Statistics 7:434-455.

Cairns, D. K. 1988. Seabirds as Indicators of Marine Food Supplies. Biological Ocenaography 5:261-271.

Cam, E., J. E. Hines, J.-Y. Monnat, J. D. Nichols, and E. Danchin. 1998. Are Adult Nonbreeders 37 
Prudent Parents? The Kittiwake Model. Ecology 79:2917.

760 Carneiro, A. P. B., A. Manica, W. Z. Trivelpiece, and R. A. Phillips. 2015. Flexibility in foraging 761 strategies of Brown Skuas in response to local and seasonal dietary constraints. Journal of 762 Ornithology 156:625-633.

763 Caswell, H. 2001. Matrix Population Models: Construction, Analysis, and Interpretation. Sinauer 764 Associates, Sunderland, Massachusetts, USA.

765 Chastel, O., H. Weimerskirch, and P. Jouventin. 1995. Influence of Body Condition on 766 Reproductive Decision and Reproductive Success in the Blue Petrel. The Auk 112:964-972.

767 Chaurand, T., and H. Weimerskirch. 1994a. The regular alternation of short and long foraging trips 768 in the blue petrel Halobaena caerulea: a previously undescribed strategy of food provisioning 769

Chaurand, T., and H. Weimerskirch. 1994b. Incubation routine, body mass regulation and egg neglect in the Blue Petrel Halobaena caerulea. Ibis 136:285-290.

772 Cherel, Y., P. Bocher, C. Trouvé, and H. Weimerskirch. 2002. Diet and feeding ecology of blue 773 petrels Halobaena caerulea at Iles Kerguelen, Southern Indian Ocean. Marine Ecology $774 \quad$ Progress Series 228:283-299.

775 Cherel, Y., M. Connan, A. Jaeger, and P. Richard. 2014. Seabird year-round and historical feeding 776 ecology: blood and feather $\delta 13 \mathrm{C}$ and $1315 \mathrm{~N}$ values document foraging plasticity of small 777 sympatric petrels. Marine Ecology Progress Series 505:267-280.

778 Cherel, Y., P. Quillfeldt, K. Delord, and H. Weimerskirch. 2016. Combination of At-Sea Activity, 38 
Geolocation and Feather Stable Isotopes Documents Where and When Seabirds Molt. $780 \quad$ Frontiers in Ecology and Evolution 4.

781 Chu, C., and P. B. Adler. 2015. Large niche differences emerge at the recruitment stage to stabilize 782 grassland coexistence. Ecological Monographs 85:373-392.

Daunt, F., V. Afanasyev, A. Adam, J. P. Croxall, and S. Wanless. 2007. From cradle to early grave: Juvenile mortality in European shags Phalacrocorax aristotelis results from inadequate development of foraging proficiency. Biology Letters 3:371-374.

Delord, K., Y. Cherel, C. Barbraud, O. Chastel, and H. Weimerskirch. 2018. High variability in migration and wintering strategies of brown skuas (Catharacta antarctica lonnbergi) in the Indian Ocean. Polar Biology 41:59-70.

Dhondt, A. A., B. Kempenaers, and F. Adriaensen. 1992. Density-dependent clutch size caused by habitat heterogeneity. Journal of Animal Ecology 61:643-648.

791 Dunstan, P. K., S. D. Foster, E. King, J. Risbey, T. J. O’Kane, D. Monselesan, A. J. Hobday, J. R. Hartog, and P. A. Thompson. 2018. Global patterns of change and variation in sea surface temperature and chlorophyll a. Scientific Reports 8:1-9.

794 Fay, R., H. Weimerskirch, K. Delord, and C. Barbraud. 2015. Population density and climate shape 795 early-life survival and recruitment in a long-lived pelagic seabird. Journal of Animal Ecology

797 Ferrer, M., and J. A. Donazar. 2015. Density-Dependent Fecundity by Habitat Heterogeneity in an Increasing Population of Spanish Imperial Eagles. Ecology 77:69-74. 
799 Frederiksen, M., M. Edwards, A. J. Richardson, N. C. Halliday, and S. Wanless. 2006. From 800 plankton to top predators: bottom-up control of a marine food web across four trophic levels. $801 \quad$ Journal of Animal Ecology 75:1259-1268.

802 Gervasi, V., E. B. Nilsen, and J. D. C. Linnell. 2015. Body mass relationships affect the age 803 structure of predation across carnivore-ungulate systems: A review and synthesis. Mammal $804 \quad$ Review 45:253-266.

805 Gille, S. T. 2002. Warming of the Southern Ocean since the 1950s. Science 295:1275-1277.

806 Gimenez, O., J. D. Lebreton, J. M. Gaillard, R. Choquet, and R. Pradel. 2012. Estimating 807 demographic parameters using hidden process dynamic models. Theoretical Population $808 \quad$ Biology 82:307-316.

809 Godfray, H. C. J., and R. M. May. 2014. Open questions: are the dynamics of ecological $810 \quad$ communities predictable? BMC Biology 12.

811 Grande, J. M., D. Serrano, G. Tavecchia, M. Carrete, O. Ceballos, R. Díaz-Delgado, J. L. Tella, 812 and J. A. Donázar. 2009. Survival in a long-lived territorial migrant: effects of life-history 813 traits and ecological conditions in wintering and breeding areas. Oikos 118:580-590.

814 Greig, S. A., J. C. Coulson, and P. Monaghan. 1983. Age-Related differences in foraging success 815 in the herring gull (Larus Argentatus). Anim. Behav. 31:1237-1243.

816 Grosbois, V., O. Gimenez, J.-M. Gaillard, R. Pradel, C. Barbraud, J. Clobert, A. P. Møller, and H. 817 Weimerskirch. 2008. Assessing the impact of climate variation on survival in vertebrate 818 populations. Biological Reviews 83:357-399. 
819 Guinet, C., O. Chastel, M. Koudil, J. P. Durbec, and P. Jouventin. 1998. Effects of warm sea-

820 surface temperature anomalies on the blue petrel at the Kerguelen Islands. Proceedings of the

$821 \quad$ Royal Society B: Biological Sciences 265:1001-1006.

822 Hamer, K. C., R. W. Furness, and R. W. G. Caldow. 1991. The effects of changes in food 823 availability on the breeding ecology of great skuas Catharacta skua in Shetland. Journal of $824 \quad$ Zoology 223:175-188.

825 Han, W., J. Vialard, M. J. McPhaden, T. Lee, Y. Masumoto, M. Feng, and W. P. M. de Ruijter.

826 2014. Indian Ocean Decadal Variability: A Review. Bull. Amer. Meteor. Soc. 95:1679-1703.

827 Harrison, X. A., J. D. Blount, R. Inger, D. R. Norris, and S. Bearhop. 2011. Carry-over effects as 828 drivers of fitness differences in animals. Journal of Animal Ecology 80:4-18.

829 Higgins, P. J., and S. J. Davied. 1996. Handbook of Australia, New Zealand \& Antarctic Birds. $830 \quad$ Vol. 3, Snipe to pigeons. Oxford University Press.

831 Hipfner, M. J., L. K. Blight, R. W. Lowe, S. I. Wilhelm, G. J. Robertson, R. T. Barrett, T. Anker832 Nilssen, and T. P. Good. 2012. Unintended consequences: How the recovery of sea eagle 833 Haliaeetus spp. populations in the northern hemisphere is affecting seabirds. Marine $834 \quad$ Ornithology 40:39-52.

835 Hoegh-Guldberg, O., and J. F. Bruno. 2010. The Impact of Climate Change on the World's Marine $836 \quad$ Ecosystems. Science 328:1523-1528.

837 Horswill, C., J. Matthiopoulos, J. A. Green, M. P. Meredith, J. Forcada, H. Peat, M. Preston, P. N. 838 Trathan, and N. Ratcliffe. 2014. Survival in macaroni penguins and the relative importance 

Journal of Animal Ecology 83:1057-1067.

841 Horswill, C., N. Ratcliffe, J. A. Green, R. A. Phillips, P. N. Trathan, and J. Matthiopoulos. 2016. 842 Unravelling the relative roles of top-down and bottom-up forces driving population change 843 in an oceanic predator. Ecology 97:1919-1928.

844 Hunter, M. D., and P. W. Price. 1992. Playing chutes and ladders: heterogeneity and the relative 845 roles of bottom-up and top-down forces in natural communities. Ecology 73:724-732.

846 Jenouvrier, S. 2013. Impacts of climate change on avian populations. Global Change Biology $847 \quad 19: 2036-2057$.

848 Jenouvrier, S., C. Barbraud, and H. Weimerskirch. 2003. Effects of climate variability on the 849

850 Jouventin, P., J. L. Mougin, J.-C. Stahl, and H. Weimerskirch. 1985. Comparative biology of the 851 burrowing petrels of the Crozet Islands. Notornis 32:157-220.

852 Krüger, O., and J. Lindström. 2001. Habitat heterogeneity affects population growth in goshawk 853 Accipiter gentilis. Journal of Animal Ecology 70:173-181.

854 Lack, D. 1967. Interrelationships in breeding adaptations as shown by marine birds. In Proceedings 855 of the International Ornithological Congress. Vol. 14, pp. 3-42. Oxford. UK: Blackwell $856 \quad$ Scientific Publications.

857 Lauria, V., M. J. Attrill, A. Brown, M. Edwards, and S. C. Votier. 2013. Regional variation in the 858 impact of climate change: Evidence that bottom-up regulation from plankton to seabirds is 

weak in parts of the Northeast Atlantic. Marine Ecology Progress Series 488:11-22.

Lovenduski, N. S., and N. Gruber. 2005. Impact of the Southern Annular Mode on Southern Ocean circulation and biology. Geophysical Research Letters 32.

Marshall, G. J. 2003. Trends in the Southern Annular Mode from Observations and Reanalyses. $863 \quad$ Journal of climate 16:4134-4143.

864 Miller, D. A. W., E. H. C. Grant, E. Muths, S. M. Amburgey, M. J. Adams, M. B. Joseph, J. H. 865 Waddle, P. T. J. Johnson, M. E. Ryan, B. R. Schmidt, D. L. Calhoun, C. L. Davis, R. N. 866 Fisher, D. M. Green, B. R. Hossack, T. A. G. Rittenhouse, S. C. Walls, L. L. Bailey, S. S. 867 Cruickshank, G. M. Fellers, T. A. Gorman, C. A. Haas, W. Hughson, D. S. Pilliod, S. J. Price,

872 Miller, T. E. X., and V. H. W. Rudolf. 2011. Thinking inside the box: community-level 873 consequences of stage-structured populations. Trends in Ecology and Evolution 26:457-466.

874 Millon, A., S. J. Petty, B. Little, O. Gimenez, T. Cornulier, and X. Lambin. 2014. Dampening prey 875 cycle overrides the impact of climate change on predator population dynamics: a long-term 876 demographic study on tawny owls. Global Change Biology 20:1770-1781.

877 Mougeot, F., and V. Bretagnolle. 2000a. Predation risk and moonlight avoidance in nocturnal 878 seabirds. Journal of Avian Biology 31:376-386. 
879 Mougeot, F., and V. Bretagnolle. 2000b. Predation as a cost of sexual communication in nocturnal 880 seabirds: an experimental approach using acoustic signals. Animal Behaviour 60:647-656.

881 Mougeot, F., F. Genevois, and V. Bretagnolle. 1998. Predation on burrowing petrels by the brown 882 skua (Catharacta skua lönnbergi) at Mayes Island, Kerguelen. Journal of Zoology 244:429883438.

884 Nevoux, M., H. Weimerskirch, and C. Barbraud. 2007. Environmental variation and experience885 related differences in the demography of the long-lived black-browed albatross. Journal of $886 \quad$ Animal Ecology 76:159-167.

887 Oken, K. L., and T. E. Essington. 2015. How detectable is predation in stage-structured 888 populations? Insights from a simulation-testing analysis. Journal of Animal Ecology 84:6088970.

890 Oro, D., N. Hernández, L. Jover, and M. Genovart. 2014. From recruitment to senescence: food 891 shapes the age-dependent pattern of breeding performance in a long-lived bird. Ecology 892 $95: 446-457$.

893 Oro, D., A. Martínez-Abraín, M. Paracuellos, J. C. Nevado, and M. Genovart. 2006. Influence of 894 density dependence on predator-prey seabird interactions at large spatio-temporal scales. 895 Proceedings of the Royal Society B: Biological Sciences 273:379-383.

896 Pacoureau, N., M. Authier, K. Delord, and C. Barbraud. 2019a. Population response of an apex 897 Antarctic consumer to its prey and climate fluctuations. Oecologia 189:279-291.

898 Pacoureau, N., K. Delord, S. Jenouvrier, and C. Barbraud. 2019b. Demographic and population 
responses of an apex predator to climate and its prey: a long-term study of South Polar Skuas. Ecological Monographs 89.

901 Pacoureau, N., E. Gaget, K. Delord, and C. Barbraud. 2019c. Prey remains of brown skua is 902 evidence of the long-term decline in burrow occupancy of blue petrels and thin-billed prions 903 at Mayes Island, Kerguelen. Polar Biology 42:1873-1879.

904 Parmelee, D. F., and P. J. Pietz. 1987. Philopatry, Mate and Nest-Site Fidelity in the Brown Skuas 905 of Anvers Island, Antartica. The Condor 89:916-919.

906 Parmesan, C. 2006. Ecological and Evolutionary Responses to Recent Climate Change. Annual 907 Review of Ecology, Evolution, and Systematics 37:637-669.

908 Perkins, A., N. Ratcliffe, D. Suddaby, B. Ribbands, C. Smith, P. Ellis, E. Meek, and M. Bolton. 909 2018. Combined bottom-up and top-down pressures drive catastrophic population declines of 910 Arctic skuas in Scotland. Journal of Animal Ecology 87:1573-1586.

911 Péron, G., and D. N. Koons. 2012. Integrated modeling of communities: parasitism, competition, 912 and demographic synchrony in sympatric ducks. Ecology 93:2456-2464.

913 Piatt, J. F., A. M. A. Harding, M. Shultz, S. G. Speckman, T. I. van Pelt, G. S. Drew, and A. B. 914 Kettle. 2007. Seabirds as indicators of marine food supplies: Cairns revisited. Marine Ecology $915 \quad$ Progress Series 352:221-234.

916 Pinaud, D., and H. Weimerskirch. 2002. Ultimate and proximate factors affecting the breeding 917 performance of a marine top-predator. Oikos 99:141-150.

918 van de Pol, M., Y. Vindenes, B.-E. Sæther, S. Engen, B. J. Ens, K. Oosterbeek, and J. M. 45 

Tinbergen. 2010. Effects of climate change and variability on population dynamics in a long$920 \quad$ lived shorebird. Ecology 91:1192-1204.

921 Pradel, R. 2005. Multievent: An Extension of Multistate Capture-Recapture Models to Uncertain 922 States. Biometrics 61:442-447.

923 Quillfeldt, P., H. Weimerskirch, K. Delord, and Y. Cherel. 2020. Niche switching and leapfrog 924 foraging: movement ecology of sympatric petrels during the early breeding season. $925 \quad$ Movement Ecology 8.

926 R Core Team. 2020. R: A Language and Environment for Statistical Computing. R Foundation for 927 Statistical Computing, Vienna, Austria.

928 Ratcliffe, N., and R. W. Furness. 1999. The effect of parental age and experimentally manipulated 929 brood size on the foraging effort and breeding performance of great skuas (Catharacta skua). $930 \quad$ Journal of Zoology 249:195-201.

931 Regehr, H. M., and W. A. Montevecchi. 1997. Interactive effects of food shortage and predation 932 on breeding failure of black-legged kittiwakes: Indirect effects of fisheries activities and 933 implications for indicator species. Marine Ecology Progress Series 155:249-260.

934 Saunders, S. P., F. J. Cuthbert, and E. F. Zipkin. 2018. Evaluating population viability and efficacy 935 of conservation management using integrated population models. Journal of Applied Ecology $936 \quad 55: 1380-1392$.

937 Schaub, M., and F. Abadi. 2011. Integrated population models: a novel analysis framework for 938 deeper insights into population dynamics. Journal of Ornithology 152:227-237. 
939 Sinclair, A. R. E., S. Mduma, and J. S. Brashares. 2003. Patterns of predation in a diverse predator$940 \quad$ prey system. Nature 425:288-290.

941 Stenseth, N. C., J. M. Durant, M. S. Fowler, E. Matthysen, F. Adriaensen, N. Jonzén, K. Chan, H. 942 Liu, J. De Laet, B. C. Sheldon, M. E. Visser, and A. A. Dhondt. 2015. Testing for effects of 943 climate change on competitive relationships and coexistence between two bird species. 944 Proceedings of the Royal Society B: Biological Sciences 282.

945 Stenseth, N. C., A. Mysterud, G. Ottersen, J. W. Hurell, K.-S. Chan, and M. Lima. 2002. 946 Ecological Effects of Climate Fluctuations. Science 297:1292-1296.

947 Stoessel, M., B. Elmhagen, M. Vinka, P. Hellström, and A. Angerbjörn. 2019. The fluctuating 948 world of a tundra predator guild: bottom-up constraints overrule top-down species 949 interactions in winter. Ecography 42:488-499.

950 Suryan, R. M., F. Sato, G. R. Balogh, K. David Hyrenbach, P. R. Sievert, and K. Ozaki. 2006. 951 Foraging destinations and marine habitat use of short-tailed albatrosses: A multi-scale 952 approach using first-passage time analysis. Deep-Sea Research Part II: Topical Studies in $953 \quad$ Oceanography 53:370-386.

954 Sydeman, W. J., E. Poloczanska, T. E. Reed, and S. A. Thompson. 2015. Climate change and 955 marine vertebrates. Science 350:772-777.

956 Thomas, C. D., A. Cameron, R. E. Green, M. Bakkenes, L. J. Beaumont, Y. C. Collingham, B. F. 957 N. Erasmus, M. Ferreira de Siquiera, A. Grainger, L. Hannah, L. Hughes, B. Huntley, A. S. 958 van Jaarsveld, G. F. Midgley, L. Miles, M. A. Ortega-Huerta, A. Townsend Peterson, O. L. 959 Phillips, and S. E. Williams. 2004. Extinction risk from climate change. Nature 427:145-148. 
960 Tuljapurkar, S., and H. Caswell. 1997. Structured-Population Models in Marine, Terrestrial, and $961 \quad$ Freshwater Systems. Chapman \& Hall, New York.

962 de Valpine, P., D. Turek, C. J. Paciorek, C. Anderson-Bergman, D. T. Lang, and R. Bodik. 2017. 963 Programming With Models: Writing Statistical Algorithms for General Model Structures 964 With NIMBLE. Journal of Computational and Graphical Statistics 26:403-413.

965 Walther, G., E. Post, P. Convey, A. Menzel, C. Parmesan, T. J. C. Beebee, J. Fromentin, O. Hoegh966 Guldberg, and F. Bairlein. 2002. Ecological responses to recent climate change. Nature $967 \quad 416: 389-395$.

968 Warham, J. 1990. The petrels: their ecology and breeding systems. Academic Press, London, UK.

969 Weimerskirch, H. 1992. Reproductive effort in long-lived birds: age-specific patterns of condition, 970 reproduction and survival in the wandering albatross. Oikos 64:464-473.

971 Weimerskirch, H., O. Chastel, L. Ackermann, T. Chaurand, F. Cuenot-Chaillet, X. Hindermeyer, 972 and J. Judas. 1994. Alternate long and short foraging trips in pelagics seabird parents. Anim. 973 Behav. 47:472-476.

974 Zipkin, E. F., and S. P. Saunders. 2018. Synthesizing multiple data types for biological 975 conservation using integrated population models. Biological Conservation 217:240-250. 


\section{$977 \quad$ Tables}

978 Table 1: Summary of the demographic parameters and their specificities (year random effect or

979 state dependence) for the two species: the Brown Skua (top) and the Blue Petrel (bottom).

980 Notations are $\widetilde{N B}$ : Nonbreeder the previous year, $\widetilde{B}$ : Breeder the previous year, $N B$ : Nonbreeder,

981 FB: Failed Breeder, SB1: Successful Breeder with one fledged chick, SB2: Successful Breeder

982 with two fledged chicks, $F B E$ : Failed Breeder at the Egg stage, $F B C$ : Failed Breeder at the Chick

983 stage and $S B$ : Successful Breeder.

\begin{tabular}{|c|c|c|c|}
\hline Species & Parameter & $\begin{array}{l}\text { Year random } \\
\text { effect }\end{array}$ & State dependence \\
\hline \multirow{6}{*}{ Skua } & Adult apparent survival $\phi_{S}$ & $\checkmark$ & $\widetilde{N B_{S} \mid \widetilde{B_{S}}}$ \\
\hline & Breeding probability $\beta_{S}$ & $\checkmark$ & $\widetilde{N B_{S}} \mid \widetilde{B_{S}}$ \\
\hline & Breeding success $\gamma_{S}$ & $\checkmark$ & $\widetilde{N B_{S} \mid \widetilde{B_{S}}}$ \\
\hline & Breeding success 2 chicks $\delta_{S}$ & $\checkmark$ & $\widetilde{N B_{S} \mid \widetilde{B_{S}}}$ \\
\hline & Detection probability $p_{S}$ & $\checkmark$ & $\widetilde{N B_{S}} \mid \widetilde{B_{S}}$ \\
\hline & Uncertain state assignment probability $u_{S}$ & $x$ & $N B_{S}\left|F B_{S}\right| S B 1_{S} \mid S B 2_{S}$ \\
\hline \multirow{6}{*}{ Petrel } & Adult apparent survival $\phi_{P}$ & $\checkmark$ & $\widetilde{N B_{P}} \mid \widetilde{B_{P}}$ \\
\hline & Breeding probability $\beta_{P}$ & $\checkmark$ & $\widetilde{N B_{P}} \mid \widetilde{B_{P}}$ \\
\hline & Hatching success $\omega_{P}$ & $\checkmark$ & $\widetilde{N B_{P}} \mid \widetilde{B_{P}}$ \\
\hline & Breeding success $\gamma_{P}$ & $\checkmark$ & $\widetilde{N B_{P}} \mid \widetilde{B_{P}}$ \\
\hline & Detection probability $p_{P}$ & $\checkmark$ & $\widetilde{\widehat{N B_{P}} \mid \widetilde{B_{P}}}$ \\
\hline & Uncertain state assignment probability $u_{P}$ & $x$ & $N B_{P}\left|F B E_{P}\right| F B C_{P} \mid S B_{P}$ \\
\hline
\end{tabular}

984

985 
986 Table 2: Summary of the covariates tested on the demographic parameters of the two species -

987 the Brown Skua (top) and the Blue Petrel (bottom) - and the time period (in months) considered

988 for each demographic parameter. Notations are PP: Predator-Prey interactions, DD: intraspecific

989 Density-Dependence, SAM: Southern Annual Mode, SSTa: Sea Surface Temperature anomalies,

990 Chla: Chlorophyll a concentration.

\begin{tabular}{llll}
\hline \hline Species & Parameter & Covariates tested & Time period \\
\hline \multirow{3}{*}{ Skua } & Adult apparent survival $\phi_{S}$ & DD $\mid \mathrm{SAM}$ & Wintering (March-September) \\
\cline { 2 - 4 } & Breeding probability $\beta_{S}$ & $\mathrm{DD} \mid \mathrm{SAM}$ & Pre-Breeding (July-November) \\
\cline { 2 - 4 } & Breeding success $\gamma_{S}$ & PP $|\mathrm{DD}| \mathrm{SAM}$ & Breeding (October-February) \\
\cline { 2 - 4 } & Breeding success 2 chicks $\delta_{S}$ & $\mathrm{PP}|\mathrm{DD}| \mathrm{SAM}$ & Breeding (October-February) \\
\hline \hline \multirow{3}{*}{ Petrel } & Adult apparent survival $\phi_{P}$ & $\mathrm{PP}|\mathrm{DD}| \mathrm{SAM}|\mathrm{SSTa}|$ Chla & Wintering (February-September) \\
\cline { 2 - 4 } & Breeding probability $\beta_{P}$ & $\mathrm{DD}|\mathrm{SAM}| \mathrm{SSTa} \mid \mathrm{Chla}$ & Pre-Breeding (August-October) \\
\cline { 2 - 4 } & Hatching success $\omega_{P}$ & $\mathrm{PP}|\mathrm{DD}| \mathrm{SAM}|\mathrm{SSTa}|$ Chla & Breeding (October - December) \\
\cline { 2 - 4 } & Breeding success $\gamma_{P}$ & $\mathrm{PP}|\mathrm{DD}| \mathrm{SAM}|\mathrm{SSTa}|$ Chla & Breeding (December-January) \\
& &
\end{tabular}

991

992 
993 Table 3: Regression coefficients estimates for the relationships between covariates (DD:

994 intraspecific Density-Dependence, PP: Predator-Prey interactions, SAM: Southern Annular

995 Mode, SSTa: Sea Surface Temperature anomalies, Chla: Chlorophyll a concentration) and

996 demographic parameters ( $\phi$ : adult apparent survival, $\beta$ : breeding probability, $\gamma$ : breeding

997 success, $\delta$ : breeding success with two chicks, $\omega$ : hatching success) for Brown Skuas (top) and

998 Blue Petrels (bottom), $\widetilde{B}$ : breeders or $\widetilde{N B}$ : non breeders the previous years. $80 \%$ credible

999 intervals that do not include zero are in bold.

\begin{tabular}{|c|c|c|c|c|c|c|c|c|c|c|c|c|c|c|c|c|c|c|c|c|}
\hline \multirow{2}{*}{$\begin{array}{l}\text { SKUA } \\
\text { Parameters }\end{array}$} & \multicolumn{4}{|c|}{ DD } & \multicolumn{4}{|c|}{ PP } & \multicolumn{4}{|c|}{ SAM } & & & & & & & & \\
\hline & slope & $\mathrm{sd}$ & $10 \%$ & $90 \%$ & slope & $\mathrm{sd}$ & $10 \%$ & $90 \%$ & slope & $\mathrm{sd}$ & $10 \%$ & $90 \%$ & & & & & & & & \\
\hline$\phi_{S, \widetilde{B}}$ & $-0,09$ & 0,11 & $-0,22$ & 0,06 & & & & & $-0,34$ & 0,34 & $-0,76$ & 0,07 & & & & & & & & \\
\hline$\phi_{S, \widetilde{N B}}$ & $-0,12$ & 0,16 & $-0,29$ & 0,10 & & & & & 0,42 & 0,65 & $-0,36$ & 1,16 & & & & & & & & \\
\hline $\boldsymbol{\beta}_{S, \widetilde{B}}$ & 0,22 & 0,22 & $-0,09$ & 0,51 & & & & & 0,28 & 0,50 & $-0,35$ & 0,92 & & & & & & & & \\
\hline$\beta_{S, \widetilde{N B}}$ & 0,09 & 0,19 & $-0,18$ & 0,32 & & & & & 0,81 & 0,52 & 0,18 & 1,45 & & & & & & & & \\
\hline$\gamma_{S, \widetilde{B}}$ & $-0,40$ & 0,13 & $-0,57$ & $-0,24$ & 0,67 & 0,17 & 0,47 & 0,89 & $-0,10$ & 0,18 & $-0,33$ & 0,13 & & & & & & & & \\
\hline$\gamma_{S, \widetilde{N B}}$ & $-0,26$ & 0,28 & $-0,59$ & 0,12 & 0,28 & 0,40 & $-0,20$ & 0,77 & $-0,24$ & 0,60 & $-0,96$ & 0,48 & & & & & & & & \\
\hline $\boldsymbol{\delta}_{S, \widetilde{B}}$ & $-0,54$ & 0,23 & $-0,86$ & $-0,25$ & 1,28 & 0,36 & 0,86 & 1,74 & $-0,29$ & 0,37 & $-0,75$ & 0,15 & & & & & & & & \\
\hline$\delta_{S, N \widetilde{B}}$ & $-0,41$ & 0,45 & $-0,96$ & 0,17 & 0,69 & 0,96 & $-0,48$ & 1,71 & $-0,53$ & 1,65 & $-2,30$ & 1,33 & & & & & & & & \\
\hline PETREL & \multicolumn{4}{|c|}{ DD } & \multicolumn{4}{|c|}{$\mathbf{P P}$} & \multicolumn{4}{|c|}{ SAM } & \multicolumn{4}{|c|}{ SSTa } & \multicolumn{4}{|c|}{ Chla } \\
\hline Parameters & slope & $\mathrm{sd}$ & $10 \%$ & $90 \%$ & slope & $\mathrm{sd}$ & $10 \%$ & $90 \%$ & slope & sd & $10 \%$ & $90 \%$ & slope & $\mathrm{sd}$ & $10 \%$ & $90 \%$ & slope & $\mathrm{sd}$ & $10 \%$ & $90 \%$ \\
\hline$\phi_{P, \widetilde{B}}$ & $-0,12$ & 0,31 & $-0,51$ & 0,26 & 0,27 & 0,25 & $-0,05$ & 0,58 & $-0,05$ & 0,39 & $-0,54$ & 0,42 & $-0,16$ & 0,23 & $-0,45$ & 0,12 & $-0,57$ & 0,46 & $-1,14$ & 0,01 \\
\hline$\phi_{P, \widetilde{N B}}$ & $-0,99$ & 0,73 & $-1,87$ & $-0,12$ & 0,73 & 0,33 & 0,27 & 1,10 & 1,37 & 2,28 & $-0,88$ & 3,88 & 0,12 & 1,00 & $-0,91$ & 1,37 & $-1,42$ & 1,46 & $-2,83$ & 0,15 \\
\hline $\boldsymbol{\beta}_{P, \widetilde{B}}$ & 0,65 & 0,23 & 0,35 & 0,95 & & & & & $-0,23$ & 0,32 & $-0,65$ & 0,17 & 0,11 & 0,24 & $-0,18$ & 0,39 & 0,36 & 0,44 & $-0,21$ & 0,88 \\
\hline$\beta_{P, \widetilde{N B}}$ & 0,34 & 0,33 & $-0,10$ & 0,74 & & & & & 0,11 & 0,37 & $-0,33$ & 0,55 & 0,31 & 0,25 & 0,03 & 0,64 & 0,78 & 0,46 & 0,24 & 1,36 \\
\hline$\omega_{P, \widetilde{B}}$ & 0,14 & 0,23 & $-0,14$ & 0,43 & 0,29 & 0,12 & 0,15 & 0,43 & 0,29 & 0,17 & 0,09 & 0,50 & 0,13 & 0,15 & $-0,06$ & 0,32 & $-0,23$ & 0,28 & $-0,56$ & 60,11 \\
\hline$\omega_{P, \widetilde{N B}}$ & $-0,39$ & 0,44 & $-0,88$ & 0,06 & 0,29 & 0,28 & $-0,05$ & 0,62 & 0,64 & 0,39 & 0,18 & 1,13 & 0,01 & 0,37 & $-0,44$ & 0,45 & $-0,26$ & 0,57 & $-0,95$ & 0,44 \\
\hline$\gamma_{P, \widetilde{B}}$ & $-0,13$ & 0,55 & $-0,76$ & 0,54 & $-0,05$ & 0,27 & $-0,37$ & 0,27 & 0,53 & 0,33 & 0,13 & 0,95 & $-0,34$ & 0,33 & $-0,74$ & 0,02 & $-0,19$ & 0,52 & $-0,79$ & 9,45 \\
\hline$\gamma_{P, \widetilde{N B}}$ & $-1,01$ & 0,56 & $-1,71$ & $-0,39$ & 0,61 & 0,30 & 0,22 & 0,99 & 0,42 & 0,48 & $-0,18$ & 0,97 & $-0,51$ & 0,47 & $-1,10$ & 0,05 & $-0,85$ & 0,77 & $-1,84$ & 40,03 \\
\hline
\end{tabular}

1000

1001

1002 


\section{Figure Legends}

1004 Figure 1: Structure of the multispecies Integrated Population Model. Squares represent the state

1005 variables, circles represent the parameters. Data and fixed values are represented with a dark

1006 background, estimated state variables and parameters with a white background. Two types of

1007 data are used, capture histories $(\mathrm{Ch})$ from capture-recapture data and count data $(Y)$. Adult

1008 apparent survival $(\phi)$, breeding probability $(\beta)$, hatching success $(\omega)$, breeding success $(\gamma)$,

1009 breeding success with two chicks $(\delta)$, juvenile apparent survival for one to four years old and

1010 older $\left(\phi_{J 1}\right.$ to $\left.\phi_{J 4}\right)$, probability of first reproduction $(\operatorname{Pr})$, state assignment probability $(u)$ and

1011 detection probability $(p)$ are parameters estimated in the model. Fecundity $(f)$ is fixed. The

1012 number of adults $\left(N_{\text {adtot }}\right)$, dead $\left(N_{\text {dead }}\right)$, alive $\left(N_{\text {alive }}\right)$, breeders $\left(N_{B}\right)$, nonbreeders $\left(N_{N B}\right)$,

1013 failed breeders $\left(N_{F B}\right)$, failed breeders at the stage egg $\left(N_{F B E}\right)$, breeders with an egg hatched

$1014\left(N_{S H}\right)$, failed breeders at the stage chick $\left(N_{F B C}\right)$, successful breeders $\left(N_{S B}\right)$, successful breeders

1015 with one chick $\left(N_{S B 1}\right)$ or with two chicks $\left(N_{S B 2}\right)$ and the number of juveniles of one year old to

1016 four years old and older $\left(N_{J 1}\right.$ to $\left.N_{J 4+}\right)$ are state variables estimated by the model. The number of

1017 immigrants $\left(N_{i m}\right)$ is a fixed vector. The blue part is for Blue Petrels and the brown part is for

1018 Brown Skuas. Interspecific relationships are represented with thick arrows.

1019 Figure 2: Effects of predator-prey relationships (top panels) and intraspecific density-dependence

1020 (bottom panel) on adult demographic parameters for the two seabirds, the Brown Skua and the

1021 Blue Petrel. Solid lines represent the estimated relationship between the covariates and the

1022 demographic parameters. Shaded areas are the 50\% and 95\% credibility intervals. Points

1023 represent demographic parameter estimates each year (21 years) plotted against covariate. Error

1024 bars are standard deviation. Prey effect on (a) the estimated breeding success probability 52 
$1025\left(\alpha_{P P_{\gamma, S, \tilde{B}}}\right)$ and (b) breeding success with two chicks for skuas that bred the previous breeding

1026 season $\left(\alpha_{P P_{\delta, S, \widetilde{B}}}\right)$. Intraspecific density-dependence effect on (c) the breeding success $\left(\alpha_{D D_{\gamma, S, \widetilde{B}}}\right)$

1027 and on (d) breeding success of skuas that were breeders the previous breeding season $\left(\alpha_{D D_{\delta, S, \widetilde{B}}}\right)$

1028 and (e) on the breeding probability of petrels that bred the previous breeding season $\left(\alpha_{D D_{\beta, P, \widetilde{B}}}\right)$. 


\section{Figures}

\section{$1030 \quad$ Figure 1}

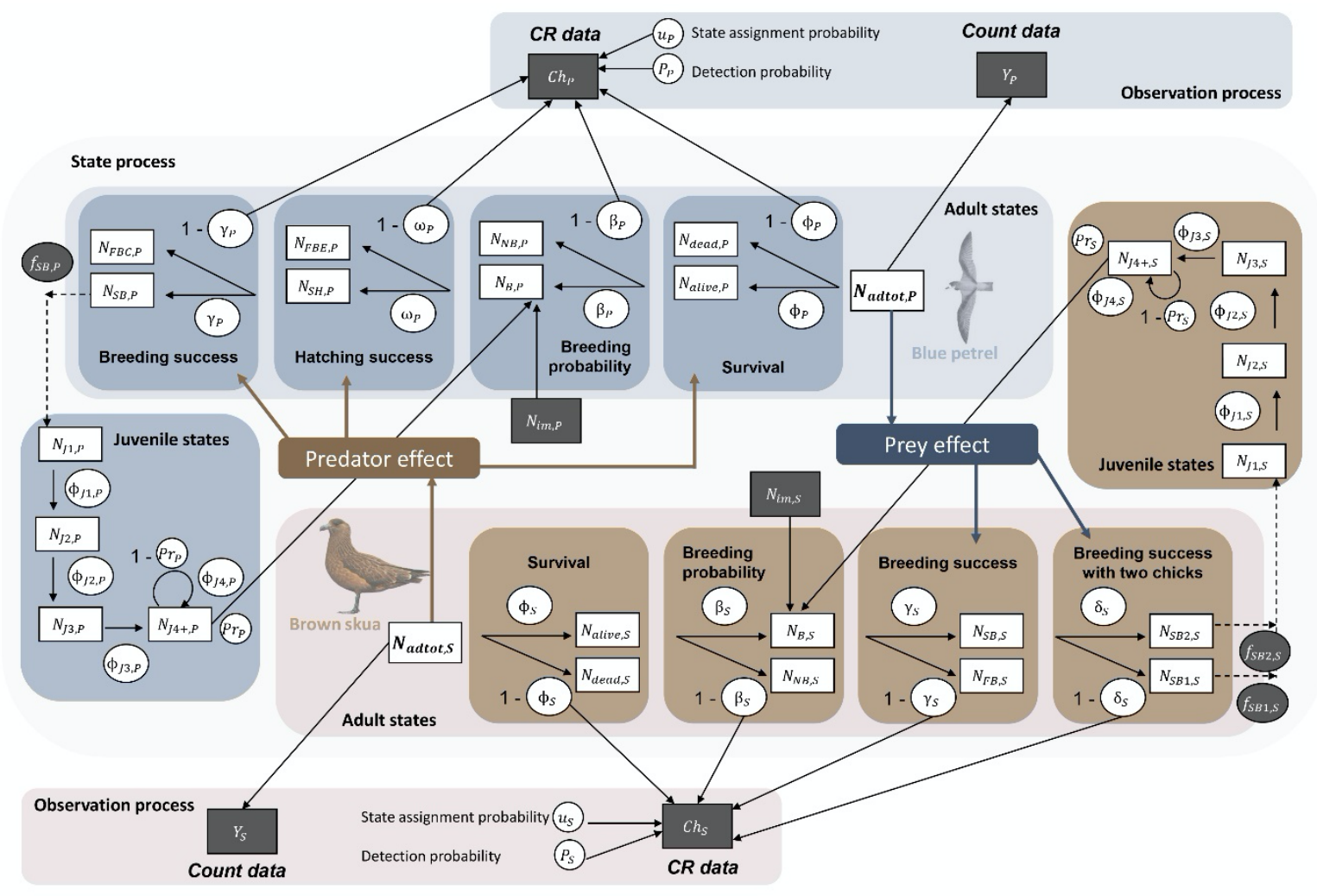




\section{Figure 2}
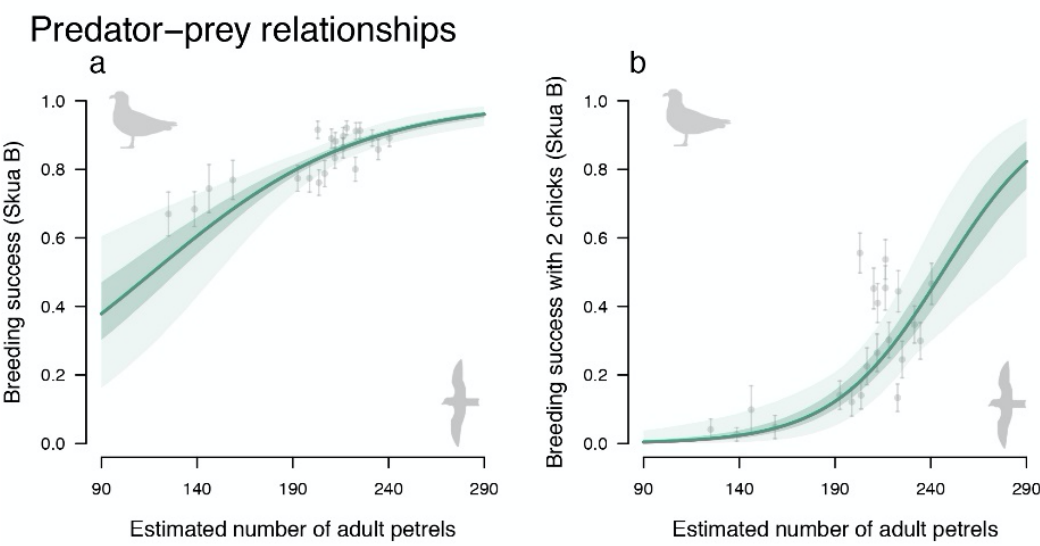

Intraspecific density-dependance
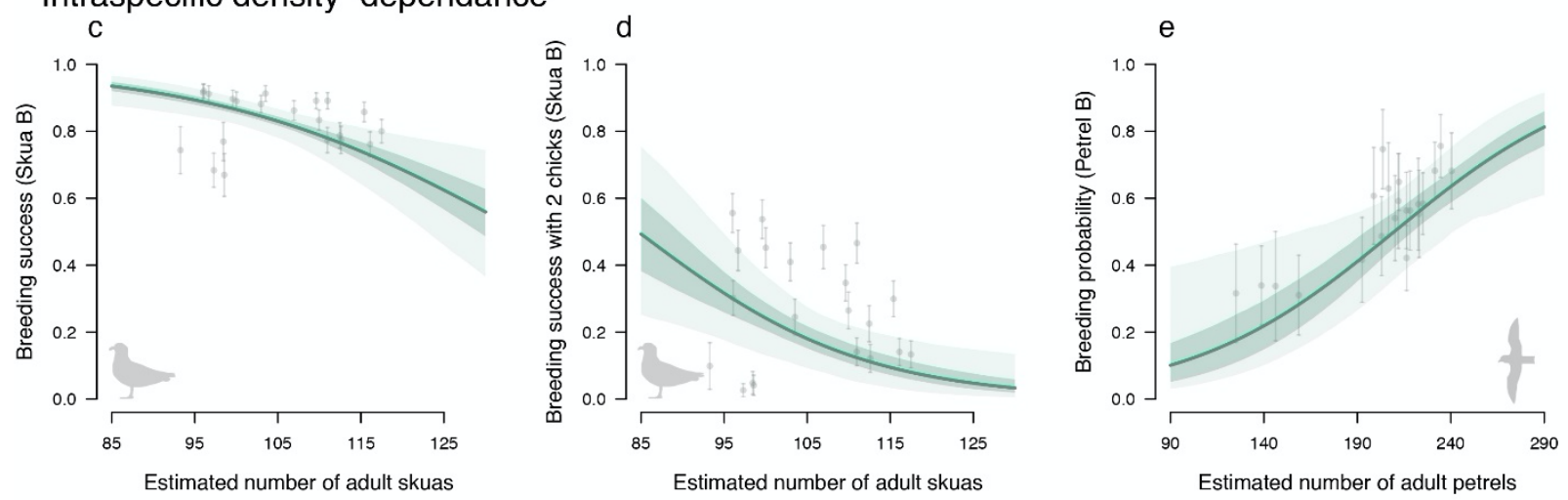

1034 